\title{
Loss potentials associated with European windstorms under future climate conditions
}

\author{
Joaquim G. Pinto ${ }^{1, *}$, Melanie K. Karremann ${ }^{1}$, Kai Born ${ }^{1}$, Paul M. Della-Marta ${ }^{2}$, \\ Matthias Klawa ${ }^{3}$
}

\author{
${ }^{1}$ Institute for Geophysics and Meteorology, University of Cologne, Kerpener Str. 13, 50937 Cologne, Germany \\ ${ }^{2}$ Partner Reinsurance Europe Limited, Bellerivestrasse 36, 8034 Zurich, Switzerland \\ ${ }^{3}$ DeutscheRück AG, Hansaallee 177, 40549 Düsseldorf, Germany
}

\begin{abstract}
Possible changes in the frequency and intensity of windstorms under future climate conditions during the 21st century are investigated based on an ECHAM5 GCM multi-scenario ensemble. The intensity of a storm is quantified by the associated estimated loss derived with using an empirical model. The geographical focus is 'Core Europe', which comprises countries of Western Europe. Possible changes of losses are analysed by comparing ECHAM5 GCM data for recent (20C, 1960 to 2000) and future climate conditions (B1, A1B, A2; 2060 to 2100), each with 3 ensemble members. Changes are quantified using both rank statistics and return periods (RP) estimated by fitting an extreme value distribution using the peak over threshold method to potential storm losses. The estimated losses for ECHAM5 20C and reanalysis events show similar statistical features in terms of return periods. Under future climate conditions, all climate scenarios show an increase in both frequency and magnitude of potential losses caused by windstorms for Core Europe. Future losses that are double the highest ECHAM5 20C loss are identified for some countries. While positive changes of ranking are significant for many countries and multiple scenarios, significantly shorter RPs are mostly found under the A2 scenario for return levels correspondent to $20 \mathrm{yr}$ losses or less. The emergence time of the statistically significant changes in loss varies from 2027 to 2100. These results imply an increased risk of occurrence of windstorm-associated losses, which can be largely attributed to changes in the meteorological severity of the events. Additionally, factors such as changes in the cyclone paths and in the location of the wind signatures relative to highly populated areas are also important to explain the changes in estimated losses.
\end{abstract}

KEY WORDS: Windstorm $\cdot$ Storm damage $\cdot$ Property losses $\cdot$ Risk $\cdot$ Extreme value analysis $\cdot$ Future climate change $\cdot$ Insurance $\cdot$ Uncertainty

Resale or republication not permitted without written consent of the publisher

\section{INTRODUCTION}

Extra-tropical cyclones belong to the most destructive natural hazards affecting Europe. For example, the storms 'Kyrill' ${ }^{1}$ (18.01.2007, dd.mm.yyyy; Fink et al. 2009) and 'Klaus' (24.01.2009; Liberato et al. 2011) have recently caused insured losses of $€ \sim 3$ to

\footnotetext{
1Since 1954, the Institute of Meteorology of the Freie Universität Berlin has named all vortices in Central Europe. This list of names is used here. Source: www.met.fu-berlin. de/adopt-a-vortex/historie/
}

3.5 billion and over $€ 1.5$ billion, respectively. Economic losses from these events are estimated to be at least twice as much as insured losses (MunichRe 2008; SwissRe 2008; Aon-Benfield 2010). The storm series of 1990 (McCallum \& Norris 1990) and 1999 (Ulbrich et al. 2001) caused economic losses of $€ \sim 10$ billion each (MunichRe 2001). Such events have caused considerable disruption to social services, public transportation and energy supply, as well as leading to a large number of fatalities. The analysis of windstorms and their effects are thus highly relevant, both from a scientific and an economic point of 
view. This is documented by several recent studies (e.g. Della-Marta et al. 2010, Pinto et al. 2010, Schwierz et al. 2010, Haylock 2011).

Within this context, an important question is the extent that storm activity in general, and for Europe in particular, is influenced by climate change. This can be addressed through the analysis of simulated cyclone activity (e.g. Bengtsson et al. 2006, Löptien et al. 2008). Currently, most general circulation models (GCMs) estimate a decrease in the total number of winter cyclones (e.g. Lambert \& Fyfe 2006, Pinto et al. 2007b). However, for some regions, e.g. the British Isles region, an increased number of intense cyclones is identified in transient GCM simulations, such as the ECHAM5/MPI-OM1 GCM (e.g. Bengtsson et al. 2006, 2009, Della-Marta \& Pinto 2009). These changes in cyclone activity are connected with an increase in wind extremes over Western and Central Europe (e.g. Leckebusch et al. 2006, Pinto et al. 2007b, Rockel \& Woth 2007). While the spatial patterns of the abovementioned signals over Western Europe are largely coherent among GCMs and regional climate models (RCMs), the magnitude of the signal clearly depends on the choice of GCMs and RCMs. Typically, changes are smaller for RCMs than for GCMs (e.g. Pryor et al. 2006, 2010, Beniston et al. 2007, Donat et al. 2010a, Goyette 2011). As a consequence, loss potential (and notably its inter-annual variability) is estimated to increase over Western Europe under future climate conditions (e.g. Leckebusch et al. 2007, Pinto et al. 2007a, Donat et al. 2011).

An important aspect within the context of extreme events, climate change and impacts is an adequate estimation of uncertainties, particularly in terms of the choice of GCMs, pre-defined forcing scenarios and initial conditions. For example, Schwierz et al. (2010) analysed an ensemble of coupled climate scenarios for 2 different GCMs (ECHAM5/MPI-OM1 and HadAM3), and identified an increase in intensity of extreme storms and associated losses over Central Europe. This effect is more pronounced for stronger (and rarer) events. In fact, extreme storms typically show the largest climate change sensitivity, but assessments have large uncertainties. Extreme value statistics (e.g. Coles 2001) have been widely used to calculate the return period (RP) of windstorms (e.g. Brodin \& Rootzen 2009, Della-Marta et al. 2009, Hofherr \& Kunz 2010, Kunz et al. 2010). In particular, Della-Marta \& Pinto (2009) quantified the changes in the intensity of storms over Western and Central Europe, identifying a statistically significant shortening of the RP of storms over this area when consider- ing the Laplacian of mean sea level pressure as a measure of cyclone intensity. Based on this evidence, it is now important to quantify possible changes of the associated event based storm losses, extending the work of the aforementioned studies (this paragraph). With this aim, the main objectives are (1) to estimate the magnitude of the projected changes in storm losses under future climate conditions, (2) to sample the uncertainty of these changes by using a multi-scenario multi-member GCM ensemble, (3) to quantify possible changes in the intensity and frequency of potential losses using different evaluation techniques and (4) to distinguish between systematic changes in potential loss associated with alterations in the severity of events and other changes associated with sampling (e.g. intense storms may by chance hit a highly populated area more frequently).

With this aim, a modified version of the empirical storm loss model by Klawa \& Ulbrich (2003), originally developed for station data, was applied. Since this first publication, the original storm loss model has been adapted for use in gridded model data and applied in a number of studies dealing with climate change impacts (e.g. Leckebusch et al. 2007, Pinto et al. 2007a, Donat et al. 2010b). Unlike those studies, our analysis focuses on event-based losses (single windstorms), not on annual aggregated losses. Further, it is not restricted to individual countries in Western Europe, and considers most of Europe. This choice is motivated by the occurrence of storms like 'Klaus', and 'Xynthia', which affected the Iberian Peninsula and the Western Mediterranean, and 'Kyrill', which also hit Eastern Europe. Eastern European countries have currently lower insured values than in Western European countries, but their economies grew much faster during the last $10 \mathrm{yr}^{\underline{2}}$, so that in the future storm losses in these countries resulting from pan European events are likely to make up a greater proportion of Europe-wide losses than in the past.

\section{DATA}

\subsection{ERA-40 and NCEP/NCAR-reanalysis}

Reanalysis data from the ERA-40-project (ERA-40) of the European Centre for Medium Range Weather Forecasts (ECMWF) and the National Center for Environmental Prediction/National Center for Atmo-

\footnotetext{
${ }^{2}$ http://epp.eurostat.ec.europa.eu/portal/page/portal/ eurostat/home
} 
spheric Research (NCEP/NCAR; hereafter NCEP) are used for model calibration and validation. ERA-40 is available 6-hourly from September 1957 to August 2002 (Uppala et al. 2005). Its spatial resolution is N80 (Gaussian grid), which is equivalent to $\sim 1.125 \times$ $1.125^{\circ}(\sim 110 \mathrm{~km}$ over Central Europe). NCEP is available from 1948 to present (Kalnay et al. 1996, Kistler et al. 2001), with a spatial resolution of T62 ( 1.875 $\times$ $1.875^{\circ} ; 180 \mathrm{~km}$ over Central Europe), and a time resolution of $6 \mathrm{~h}$. NCEP data encompasses the larger time window and is, unlike ERA-40, constantly updated. Further, its spatial resolution is similar to the considered GCM (see Section 2.2). For both datasets, 6-hourly instantaneous $10 \mathrm{~m}$ wind values are used as input for the storm loss model. This analysis is performed for the winter half year (October to March), corresponding to the period when most windstorms occur over Central Europe (Lamb 1991, Klawa \& Ulbrich 2003). For comparison with the GCM data, the 40 winters 1960/1961 to 1999/2000 are used as a reference. This period is referred to as 1960 to 2000; the same nomenclature is used for other periods.

\subsection{Climate simulations of ECHAM5/MPI-OM1}

Multi-scenario ensemble climate change experiments performed with the atmosphere-ocean coupled GCM ECHAM5/MPI-OM1 (European Centre Hamburg Model version 5/Max-Planck-Institut ocean model version 1; Jungclaus et al. 2006) are used in this study. The spectral atmospheric model ECHAM5 has 31 vertical levels and a spatial resolution of T63 (Roeckner et al. 2006), which corresponds to a spatial resolution of $1.875 \times 1.875^{\circ}(\sim 180 \mathrm{~km}$ over Central Europe). The 23-level ocean model MPI-OM1 includes a dynamic ocean sea-ice model (Marsland et al. 2003). Surface conditions and fluxes are exchanged between both components. The coupled model is hereafter referred to as ECHAM5. The ensemble of climate simulations produced for the 4 th Intergovernmental Panel on Climate Change (IPCC) Assessment Report is considered. The 3 ensemble simulations for recent climate conditions (20C, 19602000) are computed with radiative forcing according to the historical greenhouse gas concentration (GHG) and aerosol concentrations for 1860 until 2000. The initial conditions for the 3 ensemble runs are different states of the $505 \mathrm{yr}$ pre-industrial control simulation computed with constant 1860 GHG concentration. Further, 3 groups of experiments following the SRES (Special Report on Emission Scenarios; Nakićenović et al. 2000) B1, A1B and A2 up to 2100 are considered ( 3 ensemble simulations each). $\mathrm{CO}_{2}$ concentration increases from $367 \mathrm{ppm}$ in 2000 to 550 (B1), 703 (A1B) and 836 ppm (A2) in the year 2100. Wind maxima (wimax) every $6 \mathrm{~h}$ from the GCM are used as input to our loss model. This dataset corresponds to the largest value during a $6 \mathrm{~h}$ integration period derived from instantaneous values of wind speed at the internal time step of the GCM ( 15 min). A comparison between wimax and 6-hourly instantaneous values is presented in Pinto et al. (2007a).

\subsection{Insurance data and population density}

The calibration of the novel event-based storm loss model (cf. Section 3.2) is performed using data from the German Insurance Association (GDV). This dataset provides daily loss ratios for private buildings in Germany for the period 1997-2007, which were aggregated in districts. As the data is collected from most of the German insurance companies, this data set is a good index for the insured market loss in Germany. Due to the usage of loss ratios, defined as the ratio loss:insured values, inflation effects can be neglected. Other socio-economic factors that may have changed slightly during this period are also neglected.

Since insurance portfolio data are not available on a European scale, the insured values are approximated for purposes of the storm loss model by the population density. The population density for the year 1990 with $1 \times 1^{\circ}$ resolution is used (Fig. 1a), as provided by CIESIN \& CIAT (2005). The area defined as Core Europe consists of the countries Belgium, Denmark, France, Germany, Great Britain, Ireland and The Netherlands, and is depicted in yellow/ orange colours. Additional countries considered in this evaluation are illustrated in pink/red colours. Areas not considered are shown in green.

\section{METHODS}

\subsection{Storm loss model}

The original storm loss model by Klawa \& Ulbrich (2003) was first modified to consider reanalysis and GCM data (Leckebusch et al. 2007, Pinto et al. 2007a). Here, the method is further developed to estimate event-based potential losses from gridded wind data. The short description below focuses on the main assumptions of the storm loss model. Novel aspects introduced in the present study are given in Steps 3, 6 and 7 . 

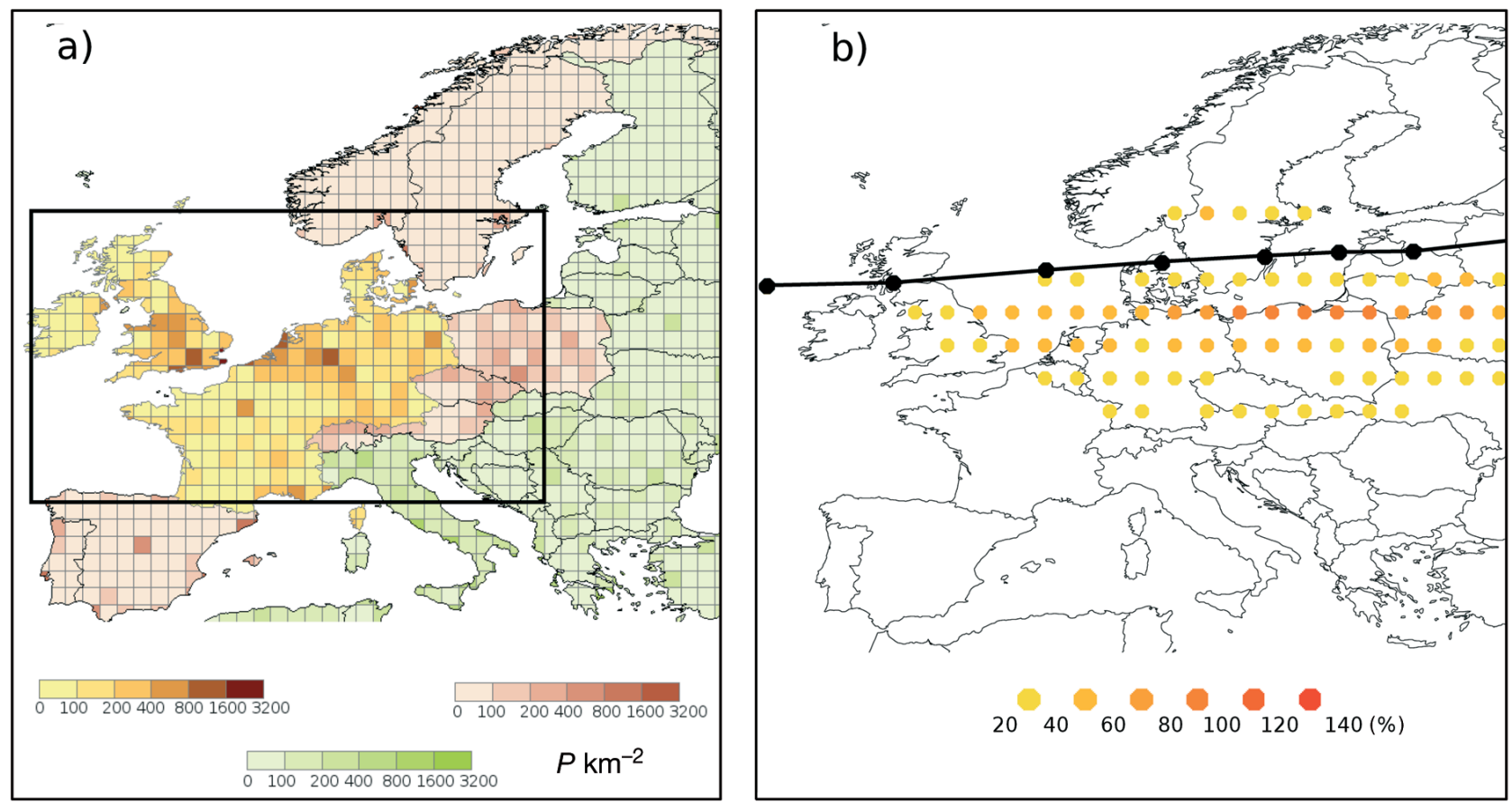

Fig. 1. (a) Population density in Europe $\left(P \mathrm{~km}^{-2}\right)$. Yellow/orange: Core Europe. Red: additional analysed countries. Green: Mediterranean and Eastern Europe. Black box: area considering a solely meteorological loss index (MI). (b) Wind signature of storm Anatol (3 December 1999). Yellow/red: points with wind values exceeding the 98th percentile in \%. Black: cyclone track of storm Anatol in 6-hourly resolution

1. The statistical model assumes that storm damages occur only at $2 \%$ of all days (Palutikof \& Skellern 1991, Klawa \& Ulbrich 2003). This definition implies that the minimum wind speed expected to produce any loss is the regional 98th percentile $\left(v_{98}\right)$ of the daily maximum wind speed. Several sensitivity studies have shown the usefulness of this assumption (e.g. Pinto et al. 2007a, Donat et al. 2010a).

2. The vulnerability of buildings to high wind speeds is dependent on local wind climate. The degree of damage increases with growing wind speeds in excess of a threshold, which indicates the minimum wind speed above which losses occur. Therefore, losses depend on both absolute wind speed and a local threshold $\left(v_{98}\right)$. The local conditions are taken into account by scaling the wind values with the local $v_{98}$.

3. A $24 \mathrm{~h}$ period is used to sample local maxima of wind speeds for a given area or country. This is performed consecutively by shifting the time window by $6 \mathrm{~h}$ each time step.

4. The cube of wind speed is proportional to the kinetic energy flux or flux density. Thus, the potential loss is estimated to increase with the cube of the maximum wind speed. This introduces a (realistic) strong non-linearity in the wind-loss relation. These values are indicated as 'raw losses'.
5. Insured losses resulting from a single windstorm depend on the values of insurance policies in the affected area. As insurance data is not available, the total value of insured property is assumed to be proportional to the local population density $\left(P_{\text {; }}\right.$ Section 2.3). Since the resolution of each atmospheric dataset is slightly different, the exact assignment between gridded wind data and $P$ boxes (done with the nearest neighbour approach) is also slightly different. This means that a single wind value for NCEP is used for more $P$ boxes than a single wind value for ERA-40.

6 . The total estimated loss for a $24 \mathrm{~h}$ window is obtained by adding the potential losses for all grid points that exceed $V_{98}$. Considering these assumptions, a moving loss index ( $L I \mathrm{raw})$ is calculated:

$$
\begin{gathered}
L I \operatorname{raw}(\text { area, } 24 \mathrm{~h})=\sum_{i=1}^{N} \sum_{j=1}^{M}\left(\frac{V_{i j}}{V_{98_{i j}}}\right)^{3} \cdot I\left(v_{i j,}, V_{98_{i j}}\right) \cdot P_{i, j} \cdot \mathrm{L}_{i, j} \\
\mathrm{~L}_{i, j}= \begin{cases}0 & \text { for seas } \\
1 & \text { for land }\end{cases} \\
I(a, b)= \begin{cases}0 & a<b \\
1 & a>b\end{cases}
\end{gathered}
$$

and $P_{i, j}=$ population density per grid box $(i, j)$

with $V_{i j}$ being the maximum wind speed within $24 \mathrm{~h}$ for each grid point, $\mathrm{M}$ and $\mathrm{N}$ being the number of grid points in the area, $\mathrm{L}_{i, j}$ being an indicator if land or sea, 
$I(a, b)$ being an indicator of whether the wind speed exceeds the 98th percentile or not, and $v_{98_{i j}}$ the 98 th percentile of daily maximum wind speed during the reference period (in this case the whole NCEP period, or 1960 to 2000 for the GCM). The resulting loss model (loss index, $L I$ ) is calibrated with historical loss values for Germany (cf. Section 3.2) via a linear regression considering historical event based losses. To reduce the data skewness, a local adjustment in loglog space was additionally performed. A final storm loss model is found with the obtained regression coefficient (A) and the constant (B):

$L I($ area, $24 \mathrm{~h})=\mathrm{A} \cdot \sum_{i=1}^{N} \sum_{j=1}^{M}\left(\frac{V_{i j}}{V_{98_{i j}}}\right)^{3} \cdot I\left(v_{i j,}, v_{98_{i j}}\right) \cdot P_{i, j} \cdot \mathrm{L}_{i, j}+\mathrm{B}$

7. In addition to the $L I$, which includes information of $P$ and which is only defined over continental areas, a meteorological index $(M I)$ is defined for a box covering most of Western Europe (cf. Fig. 1a), but considering all grid points over both land and sea, and without weighting with $P$. The definition of $M I$ is as follows:

$$
M I(\text { area, } 24 \mathrm{~h})=\sum_{i=1}^{N} \sum_{j=1}^{M}\left(\frac{V_{i j}}{V_{98_{i j}}}\right)^{3} \cdot I\left(v_{i j}, V_{98_{i j}}\right)
$$

Comparison of results using this index and the $L I$ of Core Europe allow us to quantify the relative proportion of the changes primarily due to a change in the severity of the events (e.g. larger $M I$ if storms are more intense) or to other factors (changed cyclone paths, highly populated areas like London or Paris are hit more often by chance).

\subsection{Model fitting, identification of single storm events and validation}

Following the method described in the previous sub-section, 6-hourly reanalysis $10 \mathrm{~m}$ wind data are used as input for the storm loss model. The first step is to identify the $24 \mathrm{~h}$ local wind maxima for each grid point. These values are compared to the local $v_{98}$. An example of such a wind signature for the storm Anatol (03.12.1999) can be found in Fig. 1b (similar to that presented in Fink et al. 2009, Schwierz et al. 2010). The colours indicate the magnitude of the exceedance over $v_{98}$. Next, the exceedances above $v_{98}$ for each grid point are cubed. This information indicates the meteorological characteristics of the storm, and is aggregated over the affected area, summarised as the storm index $M I$, which does not include loss data. Due to the 24-hourly sampling, the peaks included in such wind signatures have been gathered over an effective time window of $\sim 2$ calendar days over the whole area, which is approximately the time a typical windstorm needs to cross the western North Atlantic and Europe. This gives the wind signature a spatially smoothed appearance (see Fig. 1b). Another important aspect is the clustering of events (e.g. storms Lothar and Martin in France, December 1999-Ulbrich et al. 2001; or storms Vivian and Wiebke in Germany, February 1990-Lamb 1991). Our method only differentiates 2 events if they are $>24 \mathrm{~h}$ apart; otherwise they are counted as one. This time frame is just enough to separate Lothar from Martin in France. $M I$ is considered for the area defined in Fig. 1a (black box), which includes countries typically affected by windstorms and large sea areas, including the Bay of Biscay and the North Sea. The choice of a $24 \mathrm{~h}$ window is also motivated by market considerations, as it is a good compromise between the 'named perturbation' definition and the 'free hours' clause used in the insurance industry. On the other hand, a $24 \mathrm{~h}$ window is enough to capture the relevant footprint of a major windstorm, as such a storm moves rather fast, typically crossing an area the size of the MI Box (cf. Fig. 1a) in much less than $24 \mathrm{~h}$.

The loss at each grid point of a single storm event is defined as the local maximum of the $L I$ raw time series (Eq. 1). For calculating the event-based $L I$, this information is summed over the affected (continental) area. In order to obtain realistic loss values, the estimated losses have to be calibrated with real data. The $L I$ values are fitted using a linear regression with the loss ratio data of the GDV for Germany. An example for indexed event losses for Germany can be seen in Fig. 2 for using NCEP data. Since the calibration is performed using only German loss data, loss estimations for other countries may be biased. However, our simple indices $M I$ and $L I$ may be regarded as independent from any particular vulnerability definition or calibration. Therefore, the relative signals may serve as a measure of the expected climate-related changes, assuming the characteristics of private houses for Germany are representative for Western and Central Europe. Further, the climate change signal of losses is estimated solely from GCM data. The loss calibration is only important for validation purposes, and thus has no influence on the findings with respect to climate change impact.

\subsection{Ranking and extreme value statistics}

A simple and robust way to quantify changes in extreme events between 2 samples of data (e.g. 


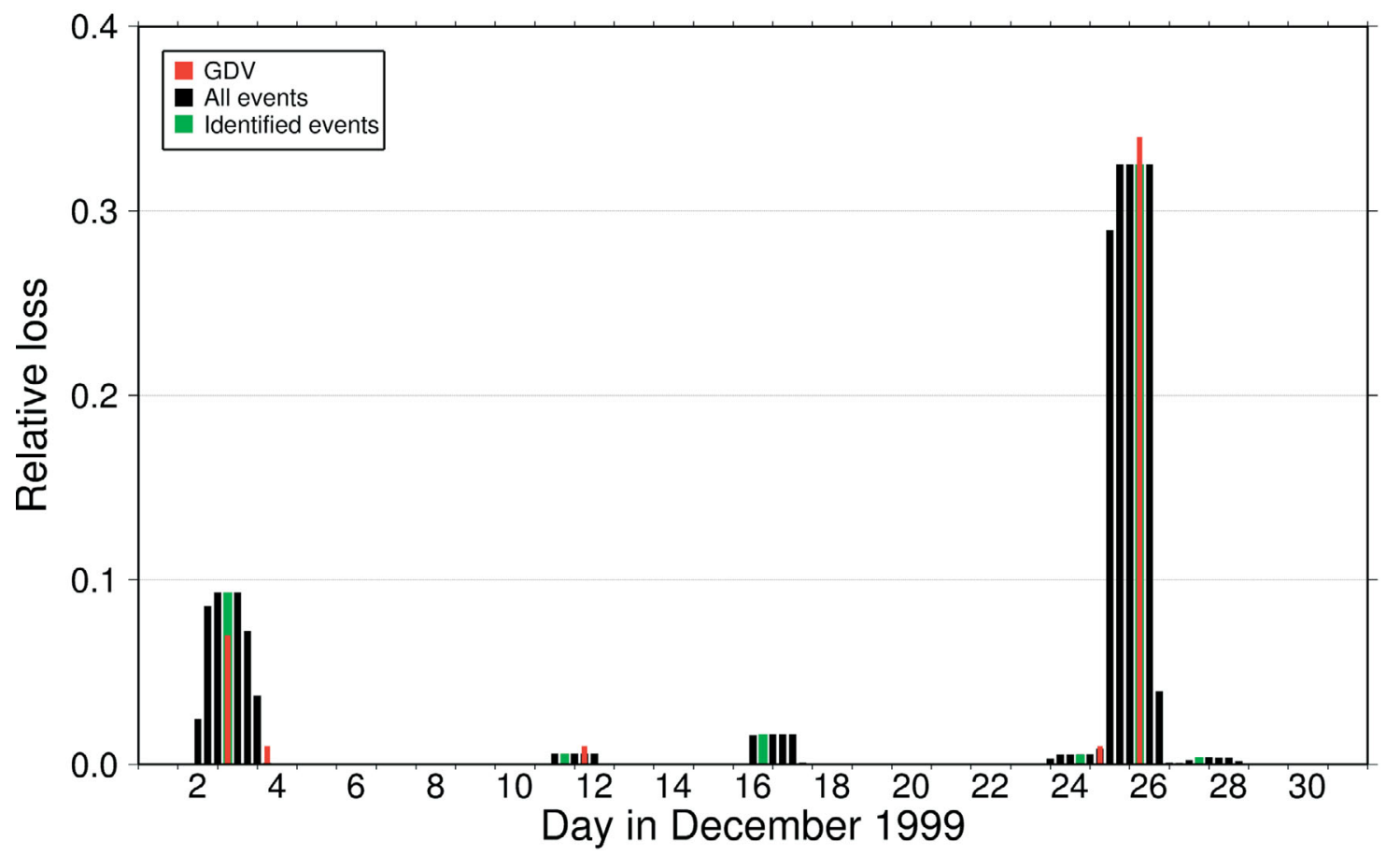

Fig. 2. Black: 24 h moving aggregated losses for Germany in December 1999. Red: historical loss data (German Insurance Association, GDV); green: identified event losses derived by NCEP. Data are relative losses to maximum loss included in the corresponding dataset

recent and future climate, or 2 reanalysis datasets) is using a statistical rank approach. This method compares the relative ranking of events (i.e. position in terms of magnitude) between datasets. Using rank statistics, no assumptions regarding statistical distributions of data are necessary to detect changes in the frequency/intensity relation over time. The Wilcoxon rank sum test (Wilcoxon 1945) allows the assessment of the significance of possible rank changes. This rank sum test is similar to the $U$-test (Mann \& Whitney 1947). The significance was tested at the $5 \%$ level (two-sided) following Table 7.29 in Sachs \& Hedderich (2009). Considered here are independent samples of the same size and with at least 5 values.

Additionally, the RPs of identified events are estimated from a generalised Pareto distribution (GPD) fitted to identified event values (green bars in Fig. 2) of the $L I$ and $M I$ indices that are above certain thresholds (the so called 'peak over threshold' method, see Appendix 1 for details of the method and selected thresholds). Following Della-Marta \& Pinto (2009), the GPD is fitted using the maximumlikelihood-method. Uncertainty is calculated using the delta-method (cf. Coles 2001, Della-Marta et al. 2009). RP distributions are significantly different at the $5 \%$ level if the $83.4 \%$ confidence interval of each RP distribution does not overlap (Julious 2004, their
Table 2). In the description of the results, changes of RPs are always considered for a given return level (e.g. the loss value for $1 \mathrm{yr}$ RP for ECHAM5 20C).

\section{EVALUATION FOR RECENT CLIMATE CONDITIONS}

In this section the loss model is evaluated on historical storm events. (1) The capability of the storm loss model to identify individual events is discussed. (2) Top loss events extracted from reanalysis data are compared to an independent ranking from MunichRe (2010). (3) Results derived from reanalysis and GCM are compared in order to identify the GCM bias.

\subsection{Identification of historical events}

The ability of the model to detect the occurrence of loss events is proved. For this purpose, the storm loss model is run with reanalysis data and the events obtained are compared to existing loss information for Germany. In general, the model is able to identify the occurrence of such events in the correct time frame, but the magnitude of the events is represented less well. This can be seen in an example for 
December 1999 based on NCEP data (Fig. 2). While the timing is correctly assessed, the magnitude of storm Lothar (26.12.1999) is underestimated, and the magnitude of storm Anatol (3.12.1999) is overestimated. Thus, the loss model generally has difficulty in capturing the lower losses (overestimation), while larger losses are typically slightly underestimated. In particular, the performance for the ERA-40 model is limited for larger losses (not shown). This can largely be attributed to the fact that the validation can only be made for 5 winters (1997/1998 to 2001/2002), and has some implications for the ranking (see Section 4.2). Such difficulties were not unexpected: severe storms typically have above average losses than what could be expected from wind gusts alone, due to market reasons (e.g. claim regulation, awareness of clients). Further, the collection of losses is more exhaustive and detailed than for minor events. For lower losses, overestimations may be largely associated with the fact that the $v_{98}$ threshold is only a rough approximation for the threshold above which losses can occur.

Thus, and given the highly non-linear response of damage to wind speed, these results are viewed as satisfactory. The authors' experience using different assumptions in distributions, vulnerability of insured values and calibrations of the loss functions for Germany and Europe suggests that a higher accuracy in loss determination will not improve the results at this spatial scale. In fact, other current state-of-the-art windstorm loss models use high resolution wind fields ( $\sim 7 \mathrm{~km}$ horizontal resolution) combined with accurate information on the distribution of buildings and their insured values as well as detailed differentiation of the vulnerability of certain building types to obtain a better agreement between modelled and actual loss (Haylock 2011). Further, the practical experience shows that the uncertainty associated with loss data is often larger than the uncertainty associated with wind data. Given the large uncertainties in any results from future climate projections, combined with uncertainties in the value, distribution and vulnerability of insured values in the future, we see the performance of the present loss model to be sufficient to explore the possible interactions between meteorological changes and the changes in loss.

\subsection{Ranking of windstorm losses for the historical period}

In a second step, losses derived from reanalysis data were ranked according to their magnitude, and compared to an independent top 10 event list from MunichRe (2010) for the period 1980-2010. The top 10 ranking events of each data source (MunichRe, NCEP, ERA-40) are shown in Table 1. The reanalysis datasets identify the larger events correctly, even though the coherence in terms of ranking is not tight. The NCEP based top 10 contain only 5 of the top 10 losses from MunichRe (2010), while all but one of the other 5 events are ordered within the first 50 events. As ERA-40 does not cover the same time period as NCEP, especially not the last $8 \mathrm{yr}$ (missing storms like Kyrill, Klaus and Xynthia), ERA-40 only has 3 events in the top 10. The strongest historical storm with respect to losses in the last $30 \mathrm{yr}$ was 'Lothar' (26.12.1999; MunichRe 2010). While this storm was on rank 7 based on the NCEP statistics, it is clearly underestimated in the ERA-40 dataset. The weak core pressure of Lothar in ERA-40 has been dis-

Table 1. Top 10 storm losses taken from MunichRe (MR; 2010) for Europe (1980-2010), and based on NCEP (1980-2010) and ERA-40 (1980-2002). Rank: storm rank based on calculated losses for NCEP; ERA-40 reanalysis. Bold: events identified by the storm loss model derived with reanalysis. N.N.: no specific name was attributed to this storm. Dates: dd.mm.yyyy. (-) Event outside the ERA-40 reanalysis period

\begin{tabular}{|c|c|c|c|c|c|c|c|}
\hline & \multicolumn{3}{|c|}{$\mathrm{MR}-$} & \multicolumn{2}{|c|}{$\longrightarrow$ NCEP } & \multicolumn{2}{|c|}{-ERA-40 } \\
\hline & Date & Event & Rank & Date & Event & Date & Event \\
\hline 1 & 26.12.1999 & Lothar & 7; 231 & 18.01.2007 & Kyrill & 25.01 .1990 & Daria \\
\hline 2 & 18.01.2007 & Kyrill & $1 ;-$ & 25.01 .1990 & Daria & 26.02 .1990 & Vivian \\
\hline 3 & 25.01 .1990 & Daria & $2 ; 1$ & 31.12 .2006 & Lotte & 23.01 .1993 & Agnes \\
\hline 4 & 28.02 .2010 & Xynthia & $49 ;-$ & 26.02 .1990 & Vivian & 08.12 .1993 & Quena \\
\hline 5 & 15.10 .1987 & $87 \mathrm{~J}$ & $179 ; 28$ & 13.01 .1984 & N.N. & 28.02 .1990 & Wiebke \\
\hline 6 & 23.01 .2009 & Klaus & $47 ;-$ & 27.12.1999 & Martin & 27.03 .1987 & N.N. \\
\hline 7 & 07.01 .2005 & Gudrun & $17 ;-$ & 26.12.1999 & Lothar & 26.12 .1998 & N.N. \\
\hline 8 & 27.12 .1999 & Martin & $6 ; 104$ & 22.01 .1995 & Urania & 03.12.1999 & Anatol \\
\hline 9 & 04.12 .1999 & Anatol & $18 ; 12$ & 31.01 .1983 & N.N. & 13.01 .1993 & Verena \\
\hline 10 & 26.02 .1990 & Vivian & $4 ; 2$ & 23.01 .1993 & Agnes & 07.02 .1990 & Judith \\
\hline
\end{tabular}


cussed in detail in Ulbrich et al. (2001). The ranking is more coherent with regard to storm 'Daria' (25.01.1990), a storm which affected a much larger area, and which ranks 3 in the MunichRe (2010) list, ranks 2 according to the NCEP results and ranks 1 for the ERA-40 output. Included in the ERA-40 top 10 are 2 Great Britain storms (27.03.1987 and 26.12.1998) with no name but which have been identified as high ranking storms by Hewston \& Dorling (2011).

An unambiguous comparison of different reanalysis datasets with respect to extreme storm events is always expected to be difficult. For example, the discrepancy of ranks of both reanalysis datasets may partly be attributed to the different numbers of grid points with wind values $>V_{98}$, and to the different assignment of population data due to the dissimilar grids. Also, the MunichRe list is not independent from economic factors such as inflation: an increase in insured values as well as changes in their geographical distribution have occurred over time. Nevertheless, the loss model identifies the most severe storm events from both reanalysis datasets, and assesses the potential loss similarly if the spatial extent of the event is large enough.

\subsection{Comparison of GCM with reanalysis results}

The magnitude of the GCM bias is estimated from reanalysis data with respect to storm loss events. First the wind climatology is discussed. Pinto et al. (2007a) investigated the spatial distribution of $V_{98}$ for both

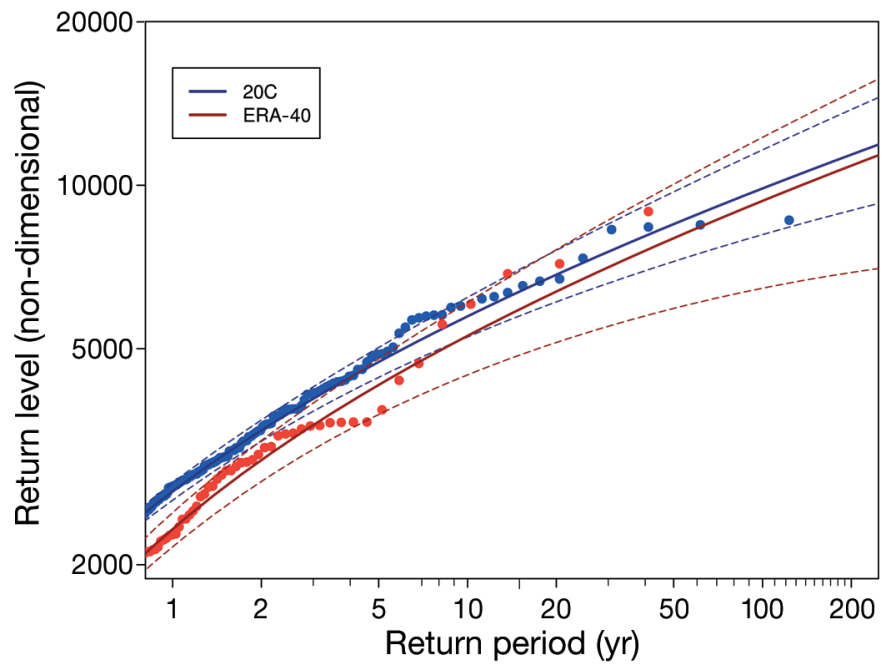

Fig. 3. Return periods (RP) of modelled losses for ERA-40 reanalysis (red) and ECHAM5 20C ensemble mean (blue). Dashed colour lines: generalized Pareto distribution fit $83.4 \%$ CI. Non-overlapping CIs for a given return level indicates differences at $5 \%$ significance level
ERA-40 and the ECHAM5 20C simulations for the period 1960-2000, representing 40 winters. Differences between the pattern of ERA-40 and 20C climate simulations are small (their Fig. 3). Over sea, and especially over the North Atlantic, the GCM overestimates wind speeds, while over the continents the values are typically underestimated, but with no strong spatial heterogeneity. This is also the case for NCEP (cf. Pinto et al. 2007b). Thus, the resulting loss based on GCM and reanalysis data may be expected to have similar statistical characteristics.

A comparison of RPs of storms obtained from the GCM and ERA-40 (using data 1960-2000) for LICore Europe results are shown in Fig. 3, where the GPD fit to ERA-40 (red) and the ECHAM5 20C ensemble mean (blue) are depicted. The GPD fit for ERA-40 uses $40 \mathrm{yr}$ of data. The fit for ECHAM5 20C considers $120 \mathrm{yr}$, as it pools together the data from 3 data samples. While the RPs obtained for GCM losses largely agree with those obtained from the reanalysis data, small differences are observed in detail. For example, significant differences exist for frequent events $(<1.7 \mathrm{yr})$, as the CIs do not overlap. Further (nonsignificant) deviations are also found around $5 \mathrm{yr}$ RPs. These differences may be partially attributed to the different sample size; in fact, they are only statistically significant for 20C runs nos. 2 and 3 (not shown). But overall, we conclude that the GCM derived losses have similar RPs to those obtained from the reanalysis data.

\section{CHANGES UNDER FUTURE CLIMATE CONDITIONS}

In this section, the impact of increasing GHG forcing on loss estimates is investigated. With this aim, changes in ranking and RPs are analysed, particularly between the end of the 21st century (2060$2100)$ and the end of the 20th century (1960-2000), both periods containing 40 full winters. Additionally, continuous changes over the whole 21st century are analysed, in order to compare the magnitude of the climate signal against natural variability. All calculations are performed considering $v_{98}$ values for recent climate conditions (no adaptation of constructions to climate change impact, cf. Pinto et al. 2007a).

\subsection{Ranking changes for Core Europe}

$M I$ and $L I$ for Core Europe are derived from the transient ECHAM5 ensemble runs following the 3 

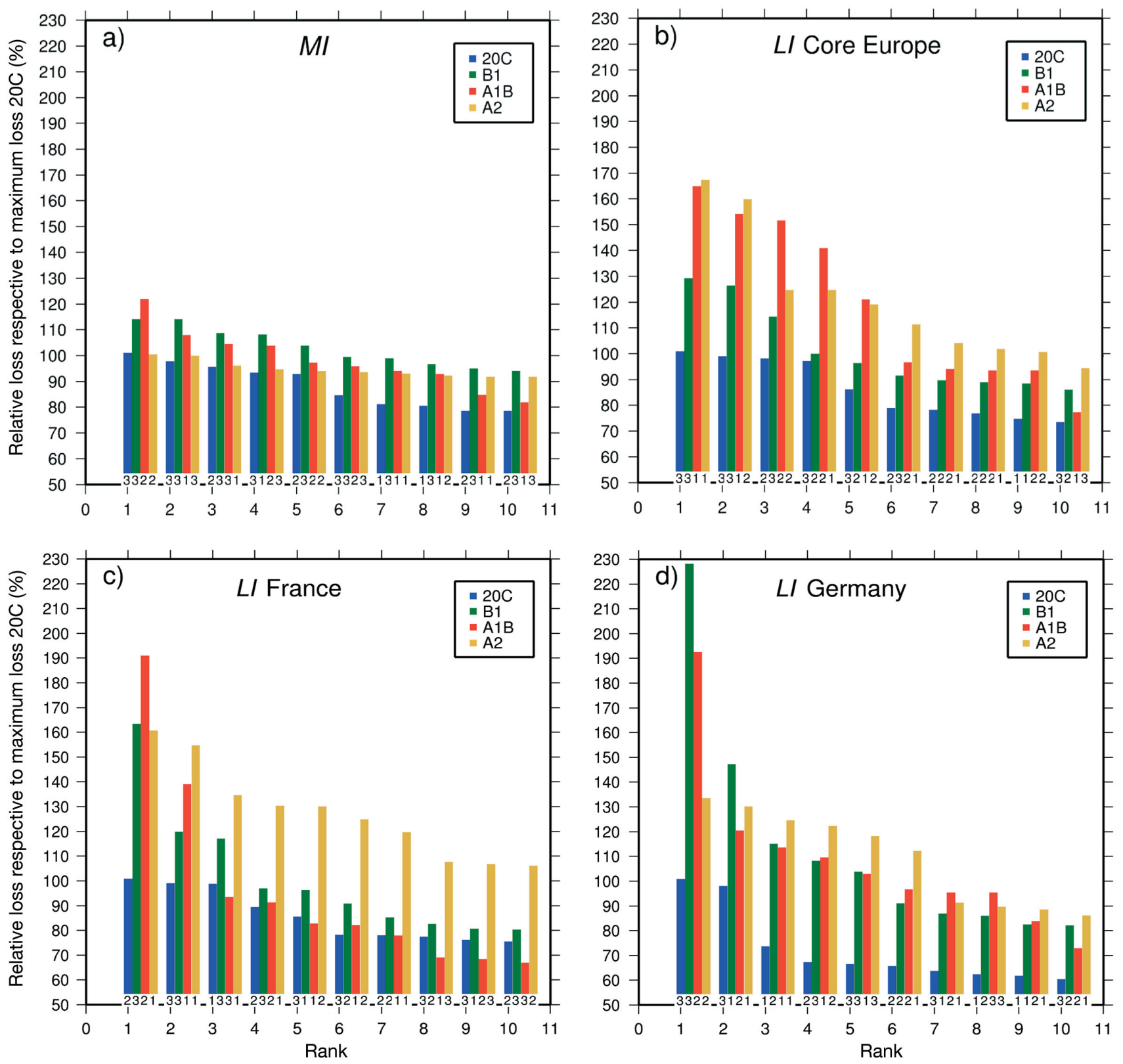

Fig. 4. Percent of loss respective to maximum loss in 20C (1960-2000) of the top 10 estimated losses for different climate scenarios (B1, A1B and A2; 2060-2100) and the present (20C) for (a) meteorological index (MI Box), (b) loss index (LI) Core Europe (see Fig. 1a), (c) LI France and (d) LIGermany. Numbers below bars: number of ensemble run

scenarios (B1, A1B and A2). In a first step, the ranking of the estimated losses is compared between the periods 2060-2100 and 1960-2000. For each scenario, data from the 3 ensemble simulation runs were pooled. The ensemble members are assumed as equally probable, and contribute to a total of $120 \mathrm{yr}$ of data. The estimated changes of severity for the top 10 events for $M I$ and $L I$ Core Europe are presented in Fig. $4 \mathrm{a}, \mathrm{b}$. To evaluate the role of single ensemble runs, each bar (representing a single loss) has a subscript number identifying the ensemble member. $M I$ and $L I$ values are shown in percent relative to the strongest event for recent climate conditions $(100 \%$, correspondent to the left blue bar). For $M I$, the strongest $20 \mathrm{C}$ value is exceeded quite often under future climate conditions, the largest value being identified for the A1B scenario with $121 \%$ (Fig. 4a). In order to quantify these changes, rank sum statistics were computed (see Section 3.3). Results show that particularly for B1 and A1B scenarios, significant changes are found from rank 5 onwards (Table 2, upper block). For the A2 scenario a shift to more 
Table 2. Significance of the change in rankings for meteorological index (MI Box; Fig. 1a), loss index ( $L I)$ Core Europe (Fig.1a), $L I$ France and $L I$ Germany. Results for each scenario B1, A1B and A2 are compared to 20C using the rank sum test, tested at the 5\% significance level. Ensembles: $\mathrm{E}=$ pooled ensembles between 2060-2100 and 1960-2000, 1-3 = results for the individual ensemble members. Data are the minimum number of rankings with a significant change, with a minimum of 5, and are the same as presented in Fig. 4

\begin{tabular}{|lccc|}
\hline Region (ensemble) & B1 & A1B & A2 \\
\hline $\boldsymbol{M I}$ Box & & & \\
$($ E) & 5 & 5 & 15 \\
$(1)$ & 5 & 5 & 5 \\
$(2)$ & 5 & 5 & 14 \\
$(3)$ & 5 & 18 & 14 \\
$\boldsymbol{L I}$ Core Europe & & & \\
$($ E) & 5 & 5 & 5 \\
$(1)$ & 5 & 5 & 5 \\
$(2)$ & 5 & 6 & 5 \\
$(3)$ & 11 & 11 & 20 \\
$\boldsymbol{L I}$ France & & & \\
$($ E) & 5 & 5 & 5 \\
$(1)$ & 5 & 10 & 5 \\
$(2)$ & 10 & 5 & 5 \\
$(3)$ & 10 & - & 10 \\
$\boldsymbol{L I}$ Germany & & & \\
$($ E) & 5 & 5 & 5 \\
$(1)$ & 5 & 5 & 5 \\
$(2)$ & 5 & 5 & 5 \\
$(3)$ & 10 & - & 10 \\
\hline
\end{tabular}

severe events is less apparent, with significant differences only from rank 15 onwards (Table 2, upper block). Interestingly, the strongest value of $20 \mathrm{C}$ is actually not exceeded for A2 (Fig. 4a). Significant changes in ranking are also found for individual runs, in most cases from rank 5 onwards, in other cases only from rank 14 (A2 runs nos. 2 and 3) or rank 18 (A1B run no. 3; Table 2). The less significant results for run no. 3 for both $\mathrm{A} 1 \mathrm{~B}$ and $\mathrm{A} 2$ scenarios are in line with the weaker changes of extreme surface winds found for these runs compared to runs nos. 1 and 2 (cf. Pinto et al. 2007a, their Fig. 5). A distinctive feature is that the top 10 for the B1 scenario is clearly dominated by run no. 3, contributing to a total of 9 out of 10 events (Fig. 4a). This demonstrates that the results show sensitivity to the choice of data, even if the 3 ensemble runs for a scenario are equally probable.

The changes for $L I$ Core Europe are shown in Table 2 and Fig. $4 \mathrm{~b}$. The changes of ranking on the pooled ensemble are significant for all 3 scenarios from rank 5 onwards (Table 2). Interestingly, changes in magnitude are quite large, reaching for example a maximum loss of $166 \%$ for the A2 scenario compared to the strongest 20C event. An exception is ensemble no. 3 for all 3 scenarios, for which changes of ranks are only significant from rank 11 (B1, A1B) or 20 (A2) onwards (Table 2). The results clearly indicate that under future climate conditions, storm events are projected to cause larger losses than in recent decades. When comparing in detail the changes in $M I$ and $L I$, 2 main differences are apparent. (1) Changes of $L I$ Core Europe are systematically comparatively larger than for $M I$ (e.g. 164 versus $121 \%$ for A1B). (2) While the tendencies between $M I$ and $L I$ Core Europe are similar, some differences are obvious, particularly for the A2 scenario, where results may appear contradictory at first sight. However, this dissimilarity is rather an indication that changes in $L I$ are not totally controlled by meteorological severity of the events (MI). The correlation coefficient between $L I$ and $M I$ is in fact only 0.784 (explained variance of $61.47 \%$ ). This means that other effects are important. A large part of the difference results from the choice of the spatial domain, particularly whether only land points are considered or not. In fact, if $M I$ is quantified only for the land areas associated with $L I$ Core Europe, the correlation raises to 0.963 (explained variance of $92.74 \%$ ). To use such an MI-land-only index would be, however, very inconvenient due to its spatially fragmented nature. Further, even over the continental areas, highly populated regions may be hit more or less frequently simply by chance. These results imply that while the $L I$ changes can be largely attributed to changes in $M I$, other factors like the exact cyclone tracks and the location of the wind signature relative to highly populated areas are also important.

In order to show how the magnitude of changes at regional scales differs from the changes for Core Europe, results for France and Germany are presented (Fig. 4c,d). In France, the magnitude of changes is larger than for Core Europe, with top events reaching 165, 193 and $162 \%$ for the 3 climate future scenarios compared to the strongest $20 \mathrm{C}$ event (Fig. 4c). The shifts of rankings are significant for all scenarios from rank 5 onwards (Table 2; LI France). Run no. 1 dominates the changes for the A2 scenario and run no. 3 for the B1 scenario. For Germany (Fig. 4d) changes of the magnitude are even larger, with the strongest loss for B1 scenario exceeding the $20 \mathrm{C}$ maximum loss by $227 \%$, thus more than doubling the $20 \mathrm{C}$ maximum loss. The magnitude changes are similar for all 3 scenarios, all significant from rank 5 onwards (Table 2; lower block). Compared to France, the strongest events are more equally distributed among the 3 runs, even though runs nos. 1 and 2 dominate for $\mathrm{A} 1 \mathrm{~B}$ and $\mathrm{A} 2$. The 

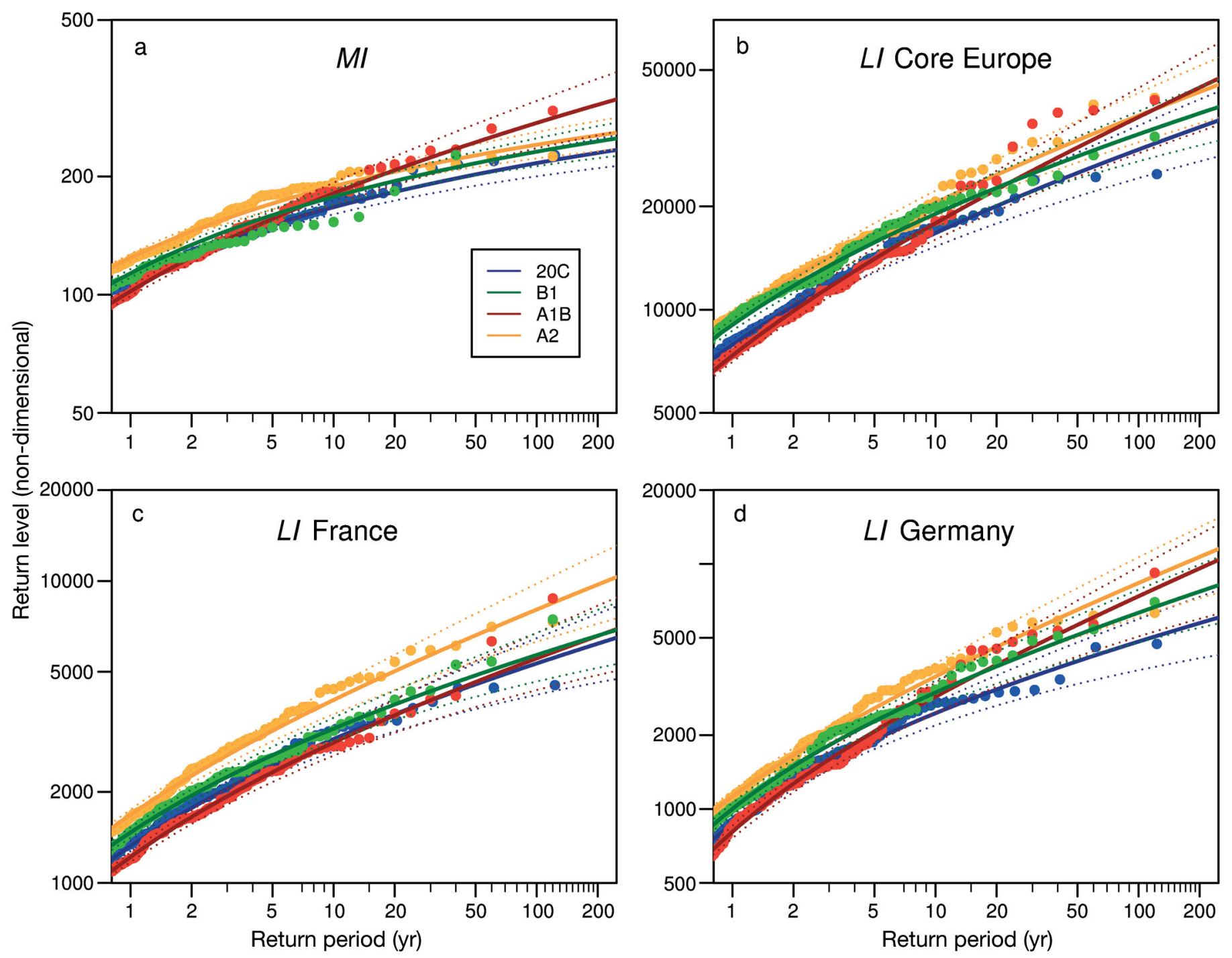

Fig. 5. As for Fig. 3, but for RP of modelled losses for 20C (1960-2000, blue), as well as climate simulations B1 (2060-2100, green), A1B (red) and A2 (yellow) for (a) MI, (b) LI Core Europe, (c) LI France and (d) LI Germany. Dashed lines: GPD fit $83.4 \%$ CI. Non-overlapping CIs for a given return level = differences at the $5 \%$ significance level

observed changes in $L I$ for Germany and France can directly be attributed to changes in the severity of events. If $M I$ is computed for France and Germany, the correlations with $L I$ is in both cases $~ 0.992$ (explained variance of $98.5 \%$ ). This means that the tightness of the relationship between $M I$ and $L I$ increases strongly for individual countries.

For other countries within Core Europe, changes are similar as for Germany and France. For countries like Denmark, The Netherlands and Belgium the changes of ranking are significant from the rank 5 to 10 onwards, independent of the scenario. An exception is Great Britain and Ireland, which show a shift to lower rankings for the A1B (Great Britain only) and A2 scenarios.

\subsection{Return period changes for Core Europe}

We analysed $M I$ and $L I$ values using extreme value statistics. In comparison to the ranking method, this approach aims to reduce the role of the sampling error and allows extrapolation of changes in RPs that are greater than the length of the data.

For $M I$, a shortening of RPs is estimated for all scenarios, except for A1B and short RPs (Fig. 5a; Table 3a). Changes towards more frequent extreme events are only significant for ECHAM5 A2 and for losses correspondent to RPs up to 35 yr for ECHAM5 $20 \mathrm{C}$ (marked red for 1 to $20 \mathrm{yr}$ in Table 3). For example, a loss value corresponding to a $20 \mathrm{yr}$ RP under current climate conditions is projected to occur for 
Table 3. Return period (RP) and CI (Lower and Upper) for given return levels of estimated losses (non-dimensional) for 20C (1960-2000) and estimated RP for the same return levels under different climate scenarios (B1, A1B and A2; 2060-2100) over meteorological index (MIBox in Fig. 1a) and loss index $(L I)$ for Core Europe (see red countries in Fig. 1a). Non-overlapping CIs for a given return level indicate differences at the $5 \%$ significance level. Significant shortening (bold) and lengthening (bold italics) of RP

\begin{tabular}{|c|c|c|c|c|c|c|c|c|c|c|c|c|}
\hline \multirow{2}{*}{$\begin{array}{l}\text { Return } \\
\text { level }\end{array}$} & \multicolumn{3}{|c|}{ ECHAM5 20C } & \multicolumn{3}{|c|}{ ECHAM5 B1 } & \multicolumn{3}{|c|}{ ECHAM5 A1B } & \multicolumn{3}{|c|}{ ECHAM5 A2 } \\
\hline & Lower & $\mathrm{RP}$ & Upper & Lower & $\mathrm{RP}$ & Upper & Lower & $\mathrm{RP}$ & Upper & Lower & $\mathrm{RP}$ & Upper \\
\hline \multicolumn{13}{|l|}{ (a) $M I$} \\
\hline 109.19 & 0.86 & 1 & 1.07 & 0.79 & 0.90 & 0.98 & 1.11 & 1.28 & 1.43 & 0.58 & 0.64 & 0.70 \\
\hline 127.56 & 1.68 & 2 & 2.24 & 1.42 & 1.65 & 1.87 & 1.91 & 2.25 & 2.64 & 1.01 & 1.15 & 1.28 \\
\hline 150.52 & 4.04 & 5 & 6.36 & 3.10 & 3.71 & 4.62 & 3.64 & 4.40 & 5.75 & 2.14 & 2.49 & 2.97 \\
\hline 166.95 & 7.75 & 10 & 15.01 & 5.54 & 6.83 & 9.68 & 5.64 & 6.98 & 10.2 & 3.77 & 4.48 & 5.93 \\
\hline 182.61 & 14.7 & 20 & 38.1 & 9.76 & 12.6 & 21.5 & 8.39 & 10.7 & 17.8 & 6.59 & 8.10 & 12.5 \\
\hline 202.18 & 33.1 & 50 & 149 & 20.2 & 28.2 & 68.6 & 13.4 & 17.9 & 36.5 & 13.6 & 17.8 & 37.1 \\
\hline 216.18 & 60.1 & 100 & $250+$ & 34.3 & 51.8 & 182.2 & 18.5 & 25.7 & 61.5 & 23.3 & 32.6 & 93.1 \\
\hline \multicolumn{13}{|c|}{ (b) LI Core Europe } \\
\hline 7901.3 & 0.87 & 1 & 1.08 & 0.68 & 0.75 & 0.82 & 1.06 & 1.20 & 1.35 & 0.58 & 0.64 & 0.70 \\
\hline 10237 & 1.71 & 5 & 2.31 & 1.25 & 1.41 & 1.61 & 1.92 & 2.22 & 2.65 & 1.08 & 1.20 & 1.36 \\
\hline 13735 & 4.14 & 5 & 6.81 & 2.85 & 3.30 & 4.25 & 4.03 & 4.81 & 6.56 & 2.42 & 2.74 & 3.45 \\
\hline 16730 & 7.95 & 10 & 16.4 & 5.35 & 6.39 & 9.53 & 6.86 & 8.43 & 13.2 & 4.40 & 5.11 & 7.22 \\
\hline 20062 & 15.0 & 20 & 41.5 & 10.1 & 12.5 & 22.9 & 11.4 & 14.5 & 26.6 & 7.92 & 9.50 & 15.5 \\
\hline 25052 & 34.0 & 50 & 152 & 23.0 & 31.2 & 80.4 & 21.5 & 29.2 & 68.0 & 17.0 & 21.5 & 44.3 \\
\hline 29325 & 62.0 & 100 & $250+$ & 42.8 & 63.1 & 224 & 34.0 & 49.0 & 138 & 29.9 & 39.9 & 100 \\
\hline
\end{tabular}

ECHAM5 A2 about every 8 yr RP. Even though changes are not statistically significant, the results suggest that for long RPs (50 and $100 \mathrm{yr}$ ) loss frequency could increase by a factor of 1.8 to 3.9 depending on the scenario.

Regarding $L I$ Core Europe, results are more diverse (Fig. 5b, Table 3b). For climate scenarios B1 and A2, shorter RPs are found in all intensities. The changes are significant for 1-4 yr losses for B1 and for 1-16 yr losses for A2. Concerning the A1B scenario, slightly higher (but non-significant) RPs are estimated $<5 \mathrm{yr}$ RPs, and shorter RPs $>5$ yr. Considering changes for RPs $\geq 50 \mathrm{yr}$, loss frequency is estimated to increase by a factor of 1.6 to 2.5 depending on the scenario. Although the present results are in line with those obtained for the ranking changes, they do present some interesting additional information about uncertainty and thus, the statistical significance of the change signal.

Regional changes within the 7 countries of Core Europe are analysed in Table 4. Results for the A2 scenario show significant shortening of RPs relative to the ECHAM5 20C return levels for losses with RPs $\leq 5$ yr for Great Britain, 8 yr for Denmark, 20 yr for The Netherlands, 26 yr for Belgium, 73 yr for France and at least 100 yr for Germany (cf. also Figs. 5c,d \& 7f). No substantial changes are found for the B1 and A1B scenarios, even though lower RPs are generally predicted for RPs $>20$ yr. For some countries (Great Britain, Germany and France) and the A1B scenario, longer (shorter) RPs are estimated for RPs below (above) 2 to 5 yr RPs. For the B1 scenario, shorter RPs are estimated for these 3 countries for all RPs, except for Great Britain for very long RPs.

The results in Table 4 partially depend on the ensemble run, and are in line with the results obtained for the rankings (Fig. 4). For example, the first run for A1B for $L I$ Core Europe shows a strong shortening of RPs, the second one slightly shorter RPs, and the third one actually longer RPs (not shown). The sensitivity of results to the ensemble run clearly indicates that climate change assessments should consider larger ensembles to explore better associated uncertainties.

\subsection{Return period changes compared to natural variability}

To estimate the emergence time at which a possible anthropogenic induced change in $M I$ and $L I$ may occur, and with the intention to separate the GHG signal from natural variability as much as possible, continuous changes over the period 1960-2100 (winter half year only) are assessed for a few selected cases. With this aim, and following Della-Marta \& Pinto (2009), a GPD is fitted to each $40 \mathrm{yr}$ period between 1960 and 2100 in which the respective year corresponds to the ending year of the period (i.e. year 2060 indicates the period 2020-2060).

We focus on the comparison of the MI versus $L I$ results for Core Europe, where partially dissimilar re- 
Table 4. As in Table 3, but for France, Germany, Great Britain, Denmark, The Netherlands, Ireland and Belgium

\begin{tabular}{|c|c|c|c|c|c|c|c|c|c|c|c|c|}
\hline \multirow{2}{*}{$\begin{array}{l}\text { Return } \\
\text { level }\end{array}$} & \multicolumn{3}{|c|}{ ECHAM5 20C } & \multicolumn{3}{|c|}{ ECHAM5 B1 } & \multicolumn{3}{|c|}{ ECHAM5 A1B } & \multicolumn{3}{|c|}{ ECHAM5 A2 } \\
\hline & Lower & $\mathrm{RP}$ & Upper & Lower & $\mathrm{RP}$ & Upper & Lower & $\mathrm{RP}$ & Upper & Lower & $\mathrm{RP}$ & Upper \\
\hline \multicolumn{13}{|l|}{ France } \\
\hline 1326.10 & 0.85 & 1 & 1.07 & 0.73 & 0.82 & 0.89 & 1.05 & 1.23 & 1.36 & 0.57 & 0.63 & 0.68 \\
\hline 1771.67 & 1.64 & 2 & 2.24 & 1.37 & 1.60 & 1.81 & 2.00 & 2.43 & 2.83 & 1.01 & 1.15 & 1.28 \\
\hline 2433.94 & 3.96 & 5 & 6.54 & 3.23 & 3.92 & 4.98 & 4.62 & 5.86 & 7.91 & 2.11 & 2.47 & 2.98 \\
\hline 2996.88 & 7.58 & 10 & 16.3 & 6.17 & 7.75 & 11.6 & 8.45 & 11.2 & 18.2 & 3.61 & 4.30 & 5.73 \\
\hline 3619.45 & 14.1 & 20 & 44.6 & 11.6 & 15.4 & 28.8 & 15.0 & 21.1 & 43.7 & 6.04 & 7.39 & 11.2 \\
\hline 4544.80 & 30.4 & 50 & 195 & 26.0 & 38.2 & 108 & 30.4 & 47.9 & 149 & 11.5 & 14.9 & 27.9 \\
\hline 5331.36 & 52.0 & 100 & $250+$ & 46.8 & 76.5 & $250+$ & 50.0 & 88.2 & $250+$ & 18.4 & 24.9 & 56.2 \\
\hline \multicolumn{13}{|c|}{ Germany } \\
\hline 873.360 & 0.85 & 1 & 1.07 & 0.74 & 0.84 & 0.91 & 0.99 & 1.14 & 1.26 & 0.62 & 0.70 & 0.76 \\
\hline 1286.98 & 1.64 & 2 & 2.24 & 1.32 & 1.55 & 1.75 & 1.75 & 2.09 & 2.43 & 1.12 & 1.28 & 1.45 \\
\hline 1915.33 & 3.96 & 5 & 6.56 & 2.84 & 3.42 & 4.28 & 3.55 & 4.37 & 5.70 & 2.33 & 2.72 & 3.36 \\
\hline 2461.08 & 7.59 & 10 & 16.1 & 5.00 & 6.18 & 8.78 & 5.79 & 7.32 & 10.9 & 3.89 & 4.62 & 6.33 \\
\hline 3076.04 & 14.1 & 20 & 43.5 & 8.61 & 11.1 & 18.7 & 9.10 & 12.0 & 20.7 & 6.28 & 7.68 & 11.9 \\
\hline 4010.25 & 30.7 & 50 & 182 & 17.1 & 23.7 & 53.6 & 15.8 & 22.2 & 48.5 & 11.4 & 14.6 & 27.4 \\
\hline 4821.66 & 52.9 & 100 & $250+$ & 28.1 & 42.0 & 123 & 23.2 & 34.7 & 92.0 & 17.3 & 23.3 & 51.3 \\
\hline \multicolumn{13}{|c|}{ Great Britain } \\
\hline 2782.57 & 0.85 & 1 & 1.07 & 0.70 & 0.79 & 0.85 & 1.02 & 1.18 & 1.31 & 0.59 & 0.65 & 0.71 \\
\hline 3671.73 & 1.64 & 2 & 2.24 & 1.30 & 1.53 & 1.72 & 1.83 & 2.21 & 2.55 & 1.11 & 1.27 & 1.42 \\
\hline 5001.65 & 3.95 & 5 & 6.49 & 3.16 & 3.83 & 4.84 & 3.90 & 4.88 & 6.41 & 2.68 & 3.20 & 3.93 \\
\hline 6139.14 & 7.57 & 10 & 16.0 & 6.28 & 7.91 & 12.0 & 6.74 & 8.73 & 13.4 & 5.35 & 6.60 & 9.33 \\
\hline 7403.91 & 14.1 & 20 & 42.7 & 12.5 & 16.8 & 33.5 & 11.3 & 15.4 & 29.3 & 10.7 & 13.9 & 24.3 \\
\hline 9295.63 & 30.8 & 50 & 178 & 30.5 & 46.9 & 161 & 21.3 & 32.0 & 86.3 & 26.8 & 38.4 & 100 \\
\hline 10913.6 & 53.4 & 100 & $250+$ & 58.9 & 105 & $250+$ & 33.3 & 55.1 & 202 & 53.3 & 84.8 & $250+$ \\
\hline \multicolumn{13}{|l|}{ Denmark } \\
\hline 260.08 & 0.85 & 1 & 1.07 & 0.73 & 0.83 & 0.90 & 1.02 & 1.18 & 1.30 & 0.57 & 0.63 & 0.68 \\
\hline 369.05 & 1.64 & 2 & 2.25 & 1.50 & 1.77 & 2.01 & 1.89 & 2.28 & 2.66 & 1.05 & 1.20 & 1.34 \\
\hline 539.57 & 3.97 & 5 & 6.56 & 4.46 & 5.53 & 7.48 & 4.22 & 5.27 & 7.05 & 2.45 & 2.87 & 3.56 \\
\hline 692.05 & 7.60 & 10 & 16.2 & 11.0 & 14.7 & 27.2 & 7.50 & 9.74 & 15.3 & 4.64 & 5.58 & 7.98 \\
\hline 868.28 & 14.2 & 20 & 43.1 & 28.2 & 42.9 & 140 & 12.9 & 17.8 & 34.2 & 8.67 & 10.9 & 19.1 \\
\hline 1144.03 & 30.8 & 50 & 175 & 100 & 209 & $250+$ & 25.5 & 38.5 & 103 & 19.4 & 26.7 & 66.2 \\
\hline 1390.62 & 53.3 & 100 & $250+$ & $250+$ & $250+$ & $250+$ & 41.2 & 68.5 & 241 & 35.1 & 52.9 & 180 \\
\hline \multicolumn{13}{|c|}{ The Netherlands } \\
\hline 2339.77 & 0.85 & 1 & 1.07 & 0.71 & 0.81 & 0.88 & 0.88 & 1.01 & 1.11 & 0.57 & 0.63 & 0.68 \\
\hline 3016.52 & 1.64 & 2 & 2.24 & 1.27 & 1.49 & 1.67 & 1.54 & 1.84 & 2.10 & 1.01 & 1.16 & 1.28 \\
\hline 4027.76 & 3.96 & 5 & 6.52 & 2.88 & 3.48 & 4.35 & 3.26 & 4.01 & 5.08 & 2.21 & 2.60 & 3.12 \\
\hline 4891.87 & 7.58 & 10 & 16.1 & 5.43 & 6.78 & 10.0 & 5.64 & 7.15 & 10.4 & 4.01 & 4.85 & 6.45 \\
\hline 5851.90 & 14.1 & 20 & 43.5 & 10.2 & 13.5 & 26.1 & 9.55 & 12.7 & 22.3 & 7.25 & 9.09 & 14.0 \\
\hline 7286.44 & 30.6 & 50 & 185 & 23.0 & 34.5 & 113 & 18.5 & 26.7 & 65.1 & 15.7 & 21.0 & 42.3 \\
\hline 8512.27 & 53.8 & 100 & $250+$ & 41.4 & 71.8 & $250+$ & 29.6 & 46.7 & 153 & 27.8 & 40.0 & 103 \\
\hline \multicolumn{13}{|l|}{ Ireland } \\
\hline 753.34 & 0.85 & 1 & 1.07 & 0.83 & 0.94 & 1.03 & 1.06 & 1.24 & 1.37 & 0.70 & 0.79 & 0.86 \\
\hline 966.31 & 1.63 & 2 & 2.22 & 1.46 & 1.73 & 1.97 & 2.08 & 2.54 & 2.96 & 1.38 & 1.62 & 1.83 \\
\hline 1256.75 & 3.90 & 5 & 6.27 & 2.96 & 3.59 & 4.50 & 4.95 & 6.33 & 8.62 & 3.40 & 4.09 & 5.34 \\
\hline 1483.41 & 7.47 & 10 & 14.9 & 4.80 & 5.96 & 8.37 & 9.16 & 12.3 & 20.5 & 6.53 & 8.17 & 13.0 \\
\hline 1716.22 & 14.0 & 20 & 38.9 & 7.49 & 9.58 & 15.5 & 16.3 & 23.3 & 51.3 & 12.1 & 16.1 & 33.9 \\
\hline 2033.73 & 31.1 & 50 & 161 & 12.7 & 17.2 & 34.9 & 32.7 & 52.9 & 187 & 26.0 & 39.0 & 136 \\
\hline 2281.51 & 54.9 & 100 & $250+$ & 18.4 & 26.1 & 63.8 & 53.1 & 96.3 & $250+$ & 44.5 & 75.1 & $250+$ \\
\hline \multicolumn{13}{|l|}{ Belgium } \\
\hline 1038.25 & 0.85 & 1 & 1.07 & 0.68 & 0.77 & 0.83 & 0.84 & 0.96 & 1.05 & 0.55 & 0.60 & 0.65 \\
\hline 1366.59 & 1.64 & 2 & 2.24 & 1.20 & 1.40 & 1.56 & 1.47 & 1.74 & 1.99 & 0.97 & 1.10 & 1.22 \\
\hline 1858.15 & 3.96 & 5 & 6.50 & 2.73 & 3.32 & 4.06 & 3.03 & 3.68 & 4.64 & 2.10 & 2.47 & 2.95 \\
\hline 2278.97 & 7.58 & 10 & 16.0 & 5.34 & 6.71 & 9.54 & 5.05 & 6.30 & 8.95 & 3.80 & 4.56 & 6.05 \\
\hline 2747.26 & 14.1 & 20 & 42.8 & 10.7 & 14.2 & 26.1 & 8.20 & 10.6 & 17.6 & 6.82 & 8.46 & 13.0 \\
\hline 3448.33 & 30.8 & 50 & 178 & 26.8 & 40.8 & 131 & 14.9 & 20.6 & 43.6 & 14.6 & 19.3 & 38.6 \\
\hline 4048.51 & 53.4 & 100 & $250+$ & 53.8 & 95.7 & $250+$ & 22.8 & 33.5 & 87.7 & 25.5 & 36.0 & 92.3 \\
\hline
\end{tabular}



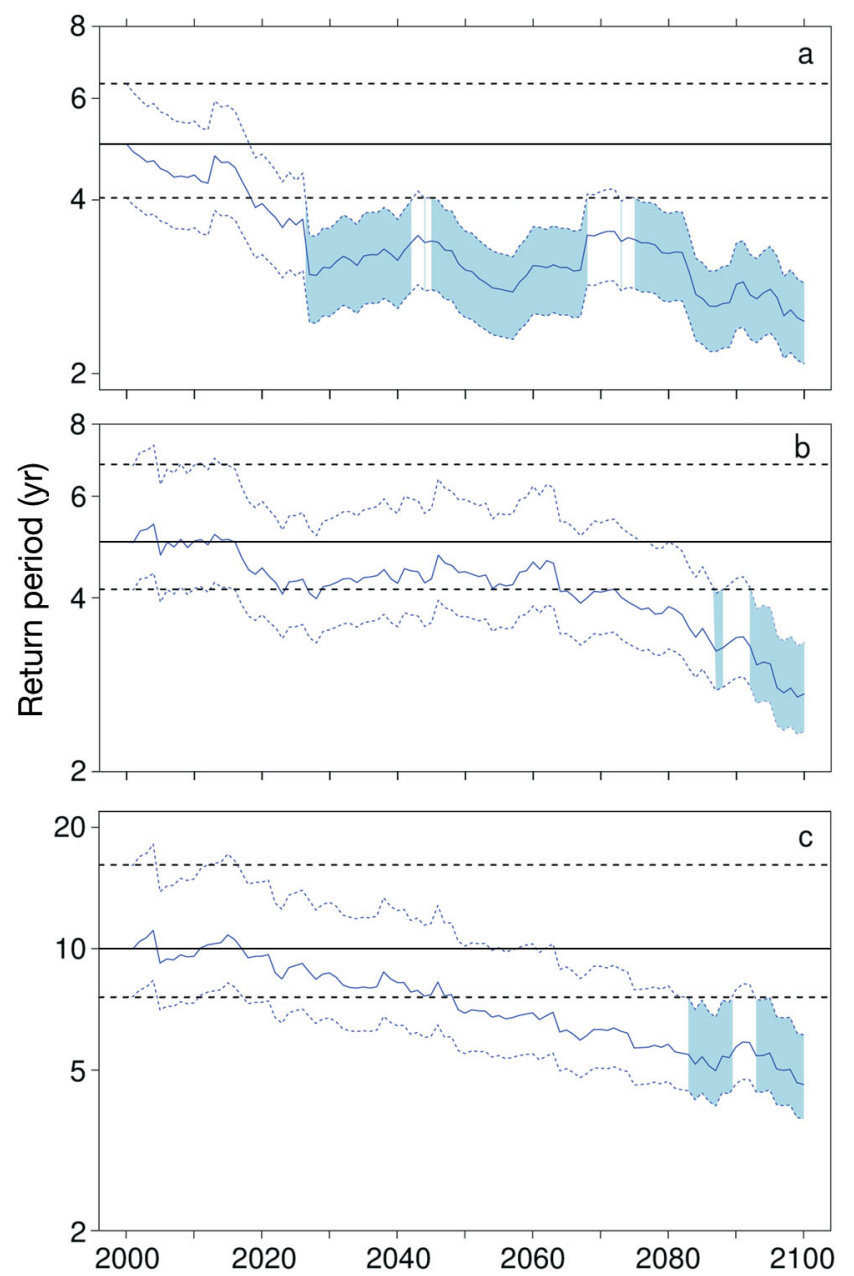

Fig. 6. Change of return period (RP; 20C and A2) over time given a certain return level corresponding to a $5 \mathrm{yr} R P$ for (a) $20 \mathrm{C}$ and $M I$, or (b) 20C and LI Core Europe; and (c) for a 10 -yr RP for 20C and LI Germany. Shown are generalised Pareto distribution fits based on moving $40 \mathrm{yr}$ climatologies. The year corresponds to the previous time period (e.g. value for the year 2000 represents time period 1960-2000). Black: 20C RP with $83.4 \%$ CIs. Blue: Estimated RP from the transient run (A2) and $83.4 \%$ CIs. Shaded: non-overlapping CIs for the given return level, indicating differences at the $5 \%$ significance level

sults were identified in the previous sections, and discuss representative examples. Fig. 6a shows the RP change (A2 scenario) for a return level corresponding to a 5 yr loss under recent climate conditions. The change of RP shows strong decadal variability superimposed on a long term trend to shorter RPs. Significantly shorter RPs for MI are identified by 2027 (corresponding to the period 1987-2027). While the changes do not always remain significant after 2027, a 20C 5 yr event becomes an event with a RP between 2.5 and $3.5 \mathrm{yr}$, reaching its lowest value by 2100 . These results are in line with Fig. 2 from Della-Marta \& Pinto (2009), which identify significant shorter RPs for cyclone intensity over this area from 2040 onwards. A more detailed analysis of the individual loss events indicates that even though MI for 2060-2100 does not exceed the strongest $20 \mathrm{C}$ storm, larger events (with a magnitude of $140 \%$ relative to the strongest $20 \mathrm{C}$ event) are found in 2027 and 2049, thus explaining the shorter RPs around this time frame. Regarding the $L I$ for Core Europe (Fig. 6b), the changes for a loss correspondent to an ECHAM5 20C 5 yr RP occur in a slower but steadier manner than for MI. A shortening of RPs is apparent from 2015 onwards, stronger after 2063, but changes are first statistically significant by 2087 (corresponding to 2047-2087), reaching a RP of $2.74 \mathrm{yr}$ by 2100. Finally, the time evolution of losses for Germany is analysed for a loss value correspondent to a $10 \mathrm{yr} R P$ (Fig. 6c). A slow decrease in estimated RPs is found along the whole time series after 2015, reaching $4.62 \mathrm{yr} R P$ by 2100 . The signal is first statistically significant by 2083, then continuously from 2093 (20532093) onwards. The evaluation of these and further examples documents that the emergence time of the statistically significant changes may occur in some cases as early as 2027, in other cases only by the end of the 21st century.

\subsection{Return period changes versus ranking changes for Europe}

Here we summarise the results obtained from the 2 different methods for all countries (see Fig. 1a; yellow and red areas). The upper row of Fig. 7 shows changes of rank statistics, whereas the lower row shows changes of RPs. Different colours correspond to different levels of change, with red tones indicating higher losses and shorter RPs, and blue tones lower losses and longer RPs. In Figs. 7a-c, dark (light) tones indicate significant (non-significant) changes to stronger events. The numbers denote the lowest number of considered ranks with significant changes (e.g. 10 events). For RPs, dark tones mark significant changes relative to a given return level for current climate conditions (cf. Tables $3 \& 4$ ), and light tones indicate non-significant changes (Fig. $7 d-f$ ). The numbers present the RP below which the changes are statistically significant (e.g. an 8 indicates that changes are significant for return levels corresponding to events between 1 and 8 yr RPs under recent climate conditions).

Consistent ranking changes towards higher losses are found for France, Germany, Denmark, Belgium, Netherlands, Austria, Switzerland, Sweden, Czech 

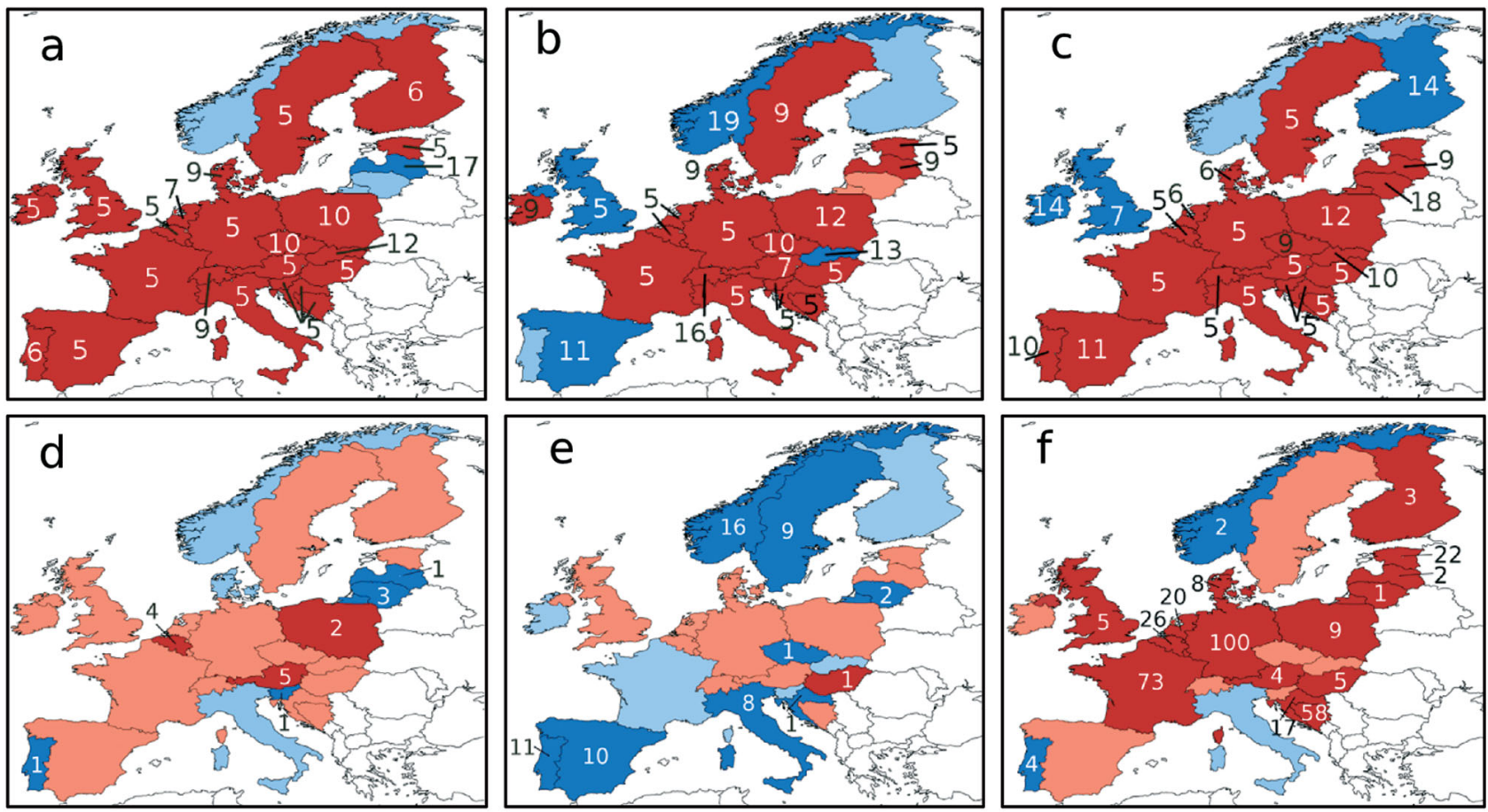

Fig. 7. (a-c) Change of ranking of the maximum loss relative to the present climate scenario (20C) for (a) B1 (b) A1B (c) A2. Dark red: significant increase in intensity of losses in relation to the present climate is estimated for future climate conditions using the rank sum test. Number: minimum number of rankings with a significant change, with a minimum of 5 . Light red: more intense events but non-significant changes. Dark blue: significant decreases in the intensity of losses for future climate conditions. Light blue: weaker events but non-significant changes. (d-f) Estimated changes of return periods (RP; yr) for given return levels under current climate conditions for (d) B1 (e) A1B (f) A2. Dark red: significant shortening of RP is found. Light red: non-significant shorter RP. Dark blue: significant longer RP. Light blue: non-significant longer RP is estimated. Numbers: RP up to which changes are significant. In all cases, pooled ensembles for 2060-2100 and 1960-2000 are compared

Republic, Croatia, Estonia, Slovenia and Bosnia, Hungary, Italy and Poland across all 3 scenarios. However, most of the above named countries do not feature significant shorter RPs, except for A2 scenario. In fact, some countries, e.g. Italy and Sweden, actually show a tendency to longer RPs (A1B scenario). On the other hand, changes for Germany are very coherent: All 3 scenarios show significant shifts rank 5 onwards, and shorter RPs are also identified in all cases (cf. Table 4), though only significant for the A2 scenario for RPs. Changes for higher RPs are often not significant due to the large uncertainties, even though the best estimate RP may change by a factor of 3 (e.g. Belgium and Germany for A1B scenario and a 100 yr RP, cf. Table 4). The apparent lack of significant results could be partially associated with the method used for CI estimation (see Appendix 1). However, the present results are largely insensitive to the choice of method due to the high number of threshold exceedances used to fit the GPD. Norway is the only country with a clear indication for lower storm risk under future climate conditions. It shows a consistent decrease of severe losses, and RPs are longer for all 3 scenarios, being largest for ECHAM5 A1B.

For Finland, Lithuania, Latvia, Slovakia, Portugal, Spain, Great Britain and Ireland, results are more sensitive to the considered scenario. For example, results for Spain show shifts of different sign for the A1B versus B1/A2 scenario. On the other hand, significant lengthening of shorter RPs are estimated for Portugal, while for Spain only the A1B scenario shows this behaviour. For Great Britain, a substantial change to a stronger magnitude is only obtained for the B1 scenario. On the other hand, a tendency to shorter RPs is found for Great Britain only for the A2 scenario, with statistically significant changes up to 5 yr RP.

Interestingly, the magnitude of changes depends only partially on the intensity of the GHG forcing. This means that changes in expected losses are not necessarily the strongest for the A2 scenario and the weakest for the B1 scenario on ensemble average. Such a result is not unexpected, as e.g. Della-Marta 
\& Pinto (2009) showed that the changes on the intensity of cyclones over Great Britain and the North Sea are statistically undistinguishable for $\mathrm{A} 1 \mathrm{~B}$ and $\mathrm{A} 2$ scenario. This indicates that the relationships between GHG forcing, cyclone activity over Western Europe and losses are far from being a simple linear relationship.

In summary, results obtained with both ranking and extreme value statistics reveal a general and consistent tendency towards an increased frequency of windstorm-related losses over most of Western, Central and Eastern Europe for B1 and A2, and slightly inconsistent findings for A1B. Further, it is clear that the detected changes in rank statistics are more sensitive to the changes in the most extreme events, while RP changes for a given return level are less sensitive to these outliers, as the GPD model is fitted on many more extremes. Finally, losses are expected to reach unseen magnitudes, which for some countries (e.g. Germany) may exceed $200 \%$ of the strongest event in present day climate simulations.

\section{SUMMARY AND CONCLUSIONS}

The main objectives of this paper was to estimate possible changes in storm losses associated with the activity of winter storm events over Europe, and identify how far these changes are statistically significant. With this aim, a methodology has been developed to estimate event-based losses. Rank statistics and extreme value analysis have been applied to a multi-scenario ECHAM5 GCM ensemble for present day and future climate conditions using the empirically calibrated loss index $L I$, which describes loss estimates based on both meteorological factors and density of insured values. In addition, an index describing purely meteorological forcing $(M I)$ of the severity function indicated to what extent such changes are primarily due to changes in cyclone activity. The main conclusions are:

(1) The simple loss model based on reanalysis data identifies storm events and is calibrated with daily loss estimations from GDV. The selection of the maximum loss value during a time window of $24 \mathrm{~h}$ declusters most observed storms.

(2) The list of storms making up the top 10 ranking estimated losses agrees with independent (not inflation-corrected) statistics (e.g. MunichRe 2010), although the ranking positions for single storms differ. The results derived from NCEP data were in better agreement with insurance industry loss estimations than those from ERA-40.
(3) Loss estimations derived from ECHAM5 GCM simulations for recent climate conditions (20C, 1960-2000) reveal a similar intensity and frequency of events as the reanalysis. The performance of the loss model is found to be sufficient to explore the possible interactions between meteorological changes and the changes in loss.

(4) Based on an ensemble of GCM simulations (20602100: B1, A1B and A2, 3 ensemble members each) the maximum storm losses of both $L I$ and $M I$ for current climate conditions are exceeded in the future climate, particularly for countries of Core Europe. Maximum losses could increase by $\sim 65 \%$ by the end of the 21 st century, according to the A1B and A2 scenarios. The significance of changes in ranking and therefore of magnitude of storms strongly depend on country and scenario. For many countries, findings point towards higher loss events, significant for at least one scenario. An exception is Norway, for which weaker losses are found.

(5) LI RPs derived from fitted GPDs show a shortening in most countries in Core Europe for a given return level, even though these changes are not always statistically significant at the end of the 21st century. Only the A2 scenario for Core Europe shows a significant shortening of RPs. In contrast to these results, the $M I$ shows significant shorter RPs as early as in the third decade of the 21st century for the same scenario.

(6) In most cases, changes in $L I$ and $M I$ are in accordance. This could be expected, as the explained variance of $M I$ in $L I$ is about $98.5 \%$ for a country like Germany or France. For the $M I$ Box and $L I$ Core Europe, the explained variance drops to $61.5 \%$. This means that the tightness of the relationship between $M I$ and $L I$ is reduced when the evaluated area increases, particularly if noncontinental areas are considered in MI. Therefore, we conclude that while events severity (expressed as $M I$ ) is a dominant driving force for the detected changes, other factors like the exact cyclone tracks and the location of the wind signatures relative to the highly populated areas become more and more important with increasing area comparatively to the $M I$ itself. From this viewpoint, factors which may partially be related with chance also represent a part of the signal in $L I$.

(7) Considering the $L I$ results of both rank statistics and extreme value analysis, 3 different tendencies can be identified: (1) Countries with shorter RPs and higher losses for all 3 climate scenarios: Germany, Belgium, Netherlands, Poland, Estland, 
Austria, Croatia, Bosnia and Hungary; (2) Norway with longer RPs and lower losses for all 3 climate scenarios; (3) All other countries have typically higher losses under future climate conditions and in some cases shorter RPs.

(8) The emergence time of statistically significant changes varies from case to case. This may occur as early as 2027 (correspondent to 1987-2027), in other cases only by the end of the current century.

(9) Although results differ between scenarios and between ensemble members, in some regions (e.g. Germany) climate change impact signals are coherent for all ensemble members of the 3 scenarios using both analysis methods. The changes in rank statistics are more sensitive to changes in possible outliers, while RP statistics are less sensitive due to the consideration of much more data to fit the GPD model.

The findings of this study are in agreement with those of Schwierz et al. (2010) who postulated increasing losses in Central Europe based on a similar approach, but using regional climate model simulations, and also with previous studies analysing windstorm associated losses on annual basis for some European countries (e.g. Leckebusch et al. 2007, Pinto et al. 2007a, Donat et al. 2011). The main advance of the present study is that it extends previous analysis of storm losses by quantifying the changes of RPs of loss events (instead of annual losses) using extreme value analysis methods. In addition, we evaluated how far the detected changes can be attributed to changes in the meteorological severity of the events $(M I)$, and which part of the changes may be caused by the effect that storms hit densely populated areas more frequently. This means that care must be used when relating and interpreting changes of RPs in cyclone activity (e.g. Della-Marta \& Pinto 2009) or event severity (MI) versus changes in RPs of potential losses $(L I)$ on regional, national and continental scale.

Within this context, it is also important to compare regional changes of cyclone intensity, extreme surface winds, $M I$ and $L I$. In general terms, the changes in extreme surface winds, $M I$ and $L I$ are expected to be in the same place. However, the strongest winds associated with a windstorm are typically found several 100s of $\mathrm{km}$ south/southwest of the cyclone centre (e.g. Fink et al. 2009). This is also seen in climatological terms (e.g. Bengtsson et al. 2009). Therefore, it is expected that the changes in extreme surface winds to be located on average several $100 \mathrm{~s}$ of $\mathrm{km}$ south/ southwest of the main changes in cyclone activity (e.g Pinto et al. 2007a,b). This means that increased cyclone intensities over Great Britain induce strong winds over Northern France, Belgium and The Netherlands and only partially over Great Britain itself. In turn this explains why losses over Great Britain only show comparatively weak changes in spite of the shorter RPs of extreme cyclones crossing over the area (e.g. Della-Marta \& Pinto 2009). In fact, the $L I$ results are largely driven by the large-scale changes in extreme wind speeds (e.g. Pinto et al. 2007b, their Fig. 9) that occur mostly over highly populated areas (e.g. London, Paris, Ruhr), while areas that experience little changes in wind speeds are comparatively sparsely populated. For this reason, the changes in $L I$ could be expected to be proportionally greater than $M I$, as found here.

Compared to other IPCC GCMs, ECHAM5 is near the average of the super-ensemble in terms of the climate signal for synoptic activity (Ulbrich et al. 2008) and thus the present results are expected to be near the ensemble mean behaviour of the IPCC GCM simulations.

The expected increase of maximum windstorm losses over Europe and, thus, shorter RPs of winter storms for certain areas during the 21st century might have a large impact on insurance companies (e.g. Changnon et al. 1997). In particular, they must assure that loss claims can be paid out without risking the solvency of the company. Financial authorities, such as the Committee of European Insurance and Occupational Pensions Supervisors, have proposed technical standards to measure the financial strength of insurance companies, which have to meet the requirements of Solvency II (Solvency Capital Requirements, QIS5 ${ }^{3}$ ). They developed a method to estimate the loss associated with a windstorm that occurs roughly every $200 \mathrm{yr}$ for national and Pan European insurers. According to insurance brokers or providers for insurance market portfolios using the QIS5 method, such a Pan-European windstorm event could cause losses around €36.1 billion" ${ }^{4}$. A 200 yr RP loss for Germany could be around $€ 9.8$ billion, and for France up to $€ 14.5$ billion $^{5}$. Under future climate conditions, the RPs of such a loss could be substantially shorter than 200 yr. Catastrophe models in insurance industry are usually based on historic loss and climatological hazard experience. Therefore, they do not

\footnotetext{
${ }^{3}$ https://eiopa.europa.eu/consultations/qis/quantitativeimpact-study-5/index.html

$\underline{4}_{\text {Www.perils.org }}$

${ }^{5}$ www.gccapitalideas.com/2010/12/02/solvency-ii-updateqis5-windstorm-scenarios-are-within-range-of-industrymodels/
} 
incorporate possible future climate estimates and trends, which might alter the risk continuously in future years. For Core Europe, the RP for large losses might change considerably already in the first half of the 21st century. Such a change is in line with results by Della-Marta \& Pinto (2009), which identified shorter RPs for intense cyclones over the study area already by 2040. Further, and by the year 2100, a 200 yr RP loss for Germany could double its value relative to recent climate conditions (inflation and changes of insurance conditions are not considered). In order to meet the additional capital requirements in a changing climate, it will be necessary to continously adapt the technical approaches to measuring windstorm risk. As it is not reasonable to calculate the risk of loss for the following year taking possible century long trends into account, it might be reasonable to base loss calculations on storm catalogues, which reflect close-future climate conditions using appropriate GCM simulations.

With this aim, future work will focus on the use of GCM data, e.g. within the new IPCC AR5 scenarios. Additional GCM ensembles could bring more information about variability of long RPs (e.g. 200 yr) and a larger number GCMs could help sample the uncertainty derived from using a single model. At the same time sensitivity analyses must combine the climate variability results with a range of simple and more complex loss models considering other possible factors affecting long term windstorm risk.

Acknowledgements. We acknowledge the provision of loss data by the German Association of Insurers ('Gesamtverband der Deutschen Versicherungswitschaft', GDV) within a project dealing with the impacts of climate change for the insurance industry in Germany ('Auswirkungen des Klimawandels auf die Schadensituation in der deutschen Versicherungswirtschaft'). The reanalysis data was obtained from the European Centre for Medium Range Weather Forecast (ECMWF) and the National Centers for Enviromental Prediction (NCEP). We thank the MPI for Meteorology (Hamburg, Germany) for support and ECHAM5 data, and the DKRZ/WDCC (Hamburg, Germany) and the ZAIK/RRZK (Cologne, Germany) for computing resources. We thank N. Gerresheim (DeutscheRück), A. Reiner (Aon-Benfield) and M. Stowasser (Allianz) for discussions. The comments of the anonymous reviewers are gratefully acknowledged.

\section{LITERATURE CITED}

Aon-Benfield (2010) Annual global climate and catastrophe report IF 2009. Publication of Aon-Benfield. Available at www.aon.com

Bengtsson L, Hodges KI, Roeckner E (2006) Storm tracks and climate change. J Clim 19:3518-3543

> Bengtsson L, Hodges KI, Keenlyside N (2009) Will extratropical storms intensify in a warmer climate? J Clim 22:
2276-2301

Beniston M, Stephenson DB, Christensen OB, Ferro CAT, and others (2007) Future extreme events in European climate: an exploration of regional climate model. Clim Change 81:71-95

Brodin E, Rootzen H (2009) Univariate and bivariate GPD methods for predicting extreme wind storm losses. Insur Math Econ 44:345-356

> Changnon SA, Changnon D, Fosse ER, Hoganson DC, Roth RJ, Totsch JM (1997) Effects of recent weather extremes on the insurance industry: major implications for the atmospheric sciences. Bull Am Meteorol Soc 78: 425-435

Coles S (2001) An introduction to statistical modeling of extreme values. Springer, London

CIESIN \& CIAT (Center for International Earth Science Information Network Columbia University; and Centro Internacional de Agricultura Tropical) (2005) Gridded population of the world, Version 3 (GPWv3): population density grids. Socioeconomic Data and Applications Center (SEDAC), Columbia University, Palisades, NY. Available at http://sedac.ciesin.columbia.edu/gpw

> Della-Marta PM, Pinto JG (2009) The statistical uncertainty of changes in winter storms over the North Atlantic and Europe in an ensemble of transient climate simulations. Geophys Res Lett 36:L14703 doi:10.1029/2009GL038557

> Della-Marta PM, Mathis H, Frei C, Liniger MA, Kleinn J, Appenzeller C (2009) The return period of wind storms over Europe. Int J Climatol 29:437-459

Della-Marta PM, Liniger MA, Appenzeller C, Bresch DN, Köllner-Heck P, Muccione V (2010) Improved estimates of the European winter windstorm climate and the risk of reinsurance loss using climate model data. J Appl Meteorol Climatol 49:2092-2120

Donat MG, Leckebusch GC, Pinto JG, Ulbrich U (2010a) European storminess and associated circulation weather types: future changes deduced from a multi-model ensemble of GCM simulations. Clim Res 42:27-43

> Donat MG, Leckebusch GC, Wild S, Ulbrich U (2010b) Benefits and limitations of regional multi-model ensembles for storm loss estimations. Clim Res 44:211-225

- Donat MG, Leckebusch GC, Wild S, Ulbrich U (2011) Future changes of European winter storm losses and extreme wind speeds in multi-model GCM and RCM simulations. Nat Hazards Earth Syst Sci 11:1351-1370

Fink AH, Brücher T, Ermert V, Krüger A, Pinto JG (2009) The European storm Kyrill in January 2007: synoptic evolution and considerations with respect to climate change. Nat Hazards Earth Syst Sci 9:405-423

Goyette S (2011) Synoptic conditions of extreme windstorms over Switzerland in a changing climate. Clim Dyn 36: 845-866

Haylock MR (2011) European extra-tropical storm damage risk from a multimodel ensemble of dynamically-downscaled global climate models. Nat Hazards Earth Syst Sci 11:2847-2857

> Hewston R, Dorling SR (2011) An analysis of observed daily maximum wind gusts in the UK. J Wind Eng Ind Aerodyn 99:845-856

> Hofherr T, Kunz M (2010) Extreme wind climatology of winter storms in Germany. Clim Res 41:105-123

Julious SA (2004) Using confidence intervals around individual means to assess statistical significance between two means. Pharm Stat 3:217-222

> Jungclaus JH, Keenlyside N, Botzet M, Haak H and others (2006) Ocean circulation and tropical variability in the coupled model ECHAM5/MPI-OM. J Clim 19:3952-3972 
Kalnay E, Kanamitsu M, Kistler R, Collins W and others (1996) The NCEP-NCAR 40-year reanalysis project. Bull Am Meteorol Soc 77:437-472

Kistler R, Collins W, Saha S, White G and others (2001) The NCEP/NCAR 50-year reanalysis: monthly-means CDROM and documentation. Bull Am Meteorol Soc 82: 247-267

Klawa M, Ulbrich U (2003) A model for the estimation of storm losses and the identification of severe winter storms in Germany. Nat Hazards Earth Syst Sci 3:725-732

Kunz M, Mohr S, Rauthe M, Lux R, Kottmeier C (2010) Assessment of extreme wind speeds from regional climate model. 1. Estimation of return values and their evaluation. Nat Hazards Earth Syst Sci 10:907-922

Lamb HH (1991) Historic storms of the North Sea, British Isles, and Northwest Europe. Cambridge University Press, Cambridge

Lambert SJ, Fyfe JC (2006) Changes in winter cyclone frequencies and strengths simulated in enhanced greenhouse warming experiments: results from the models participating in the IPCC diagnostic exercise. Clim Dyn 26:713-728

> Leckebusch GC, Koffi B, Ulbrich U, Pinto JG, Spangehl T, Zacharias S (2006) Analysis of frequency and intensity of European winter storm events from a multi-model perspective, at synoptic and regional scales. Clim Res 31: $59-74$

Leckebusch GC, Ulbrich U, Fröhlich EL, Pinto JG (2007) Property loss potentials for European mid-latitude storms in a changing climate. Geophys Res Lett 34:L05703. doi: 10.1029/2006GL027663

Liberato MRL, Pinto JG, Trigo IF, Trigo RM (2011) Klaus: an exceptional winter storm over Northern Iberia and Southern France. Weather 66:330-334

Löptien U, Zolina O, Gulev SK, Latif M, Soloviov V (2008) Cyclone life cycle characteristics over the northern hemisphere in coupled GCMs. Clim Dyn 31:507-532

Mann HB, Whitney DR (1947) On a test of whether one of two random variables is stochastically larger than the other. Ann Math Stat 18:50-60

Marsland SJ, Haak H, Jungclaus JH, Latif M, Röske F (2003) The Max-Planck-Institute global ocean-sea ice model with orthogonal curvilinear coordinates. Ocean Model 5: 91-127

McCallum E, Norris WJT (1990) The storms of January and February 1990. Meteorol Mag 119:201-210

MunichRe (2001) Winter storms in Europe. II. Analysis of 1999 losses and loss potentials. Publication of Munich Re. Available at www.munichre.com

MunichRe (2008) Die 10 teuersten Naturkatastrophen 2007. Publication of Munich Re. Available at www.munichre. com

MunichRe (2010) Significant European winter storms 1980June 2010. Overall losses. Available at www.munichre. com/app_pages/www/@res/pdf/natcatservice/significant_ natural_catastrophes/significant_winter_storms_europe_ overall_losses_july2010_de.pdf (in German)
Nakićenović N, Alcamo J, Davis G, de Vries B and others (2000) IPCC Special Report on Emissions Scenarios. Cambridge University Press, Cambridge

Palutikof JP, Skellern AR (1991) Storm severity over Britain: a report to Commercial Union. Climatic Research Unit, University of East Anglia, Norwich

> Pinto JG, Fröhlich EL, Leckebusch GC, Ulbrich U (2007a) Changes in storm loss potentials over Europe under modified climate conditions in an ensemble of simulations of ECHAM5/MPI-OM1. Nat Hazards Earth Syst Sci 7:165-175

Pinto JG, Ulbrich U, Leckebusch GC, Spangehl T, Reyers M, Zacharias S (2007b) Changes in storm track and cyclone activity in three SRES ensemble experiments with the ECHAM5/MPI-OM1 GCM. Clim Dyn 29:195-210

Pinto JG, Neuhaus CP, Leckebusch GC, Reyers M, Kerschgens M (2010) Estimation of wind storm impacts over West Germany under future climate conditions using a statistical-dynamical downscaling approach. Tellus, Ser A, Dyn Meterol Oceanogr 62:188-201

Pryor SC, Schoof JT, Barthelmie RJ (2006) Winds of change? Projections of near-surface winds under climate change scenarios. Geophys Res Lett 33:L11702. doi:10.1029/2006 GL026000

Pryor SC, Barthelmie RJ, Clausen NE, Drews M, MacKellar N, Kjellström E (2010) Analyses of possible changes in intense and extreme wind speeds over northern Europe under climate change scenarios. Clim Dyn 38:189-208

Rockel B, Woth K (2007) Future changes in near surface wind speed extremes over Europe from an ensemble of RCM simulations. Clim Change 81:267-280

Roeckner E, Brokopf R, Esch M, Giorgetta M and others (2006) Sensitivity of simulated climate to horizontal and vertical resolution in the ECHAM5 atmosphere model. J Clim 19:3771-3791

Sachs L, Hedderich J (2009) Angewandte Statistik: Methodensammlung mit R. Springer-Verlag, Berlin

Schwierz C, Köllner-Heck P, Zenklusen Mutter E, Bresch DN, Vidale PL, Wild M, Schär C (2010) Modelling European winter wind storm losses in current and future climate. Clim Change 101:485-514

SwissRe (2008) Natural catastrophes and man-made disasters in 2007: high losses in Europe. Sigma, Nr. 1/2008. Swiss Re publishing. Available at www.swissre.com/ sigma/?year=2008\#

Ulbrich U, Fink AH, Klawa M, Pinto JG (2001) Three extreme storms over Europe in December 1999. Weather 56:70-80

> Ulbrich U, Pinto JG, Kupfer H, Leckebusch GC, Spangehl T, Reyers M (2008) Changing Northern Hemisphere storm tracks in an ensemble of IPCC climate change simulations. J Clim 21:1669-1679

Uppala SM, Kallberg P, Hernandez A, Saarinen S and others (2005) The ERA-40 reanalysis. Q J R Meteorol Soc 131: 2961-3012

> Wilcoxon F (1945) Individual comparisons by ranking methods. Biom Bull 1:80-83 
APPENDIX 1. Details of GDP fitting and selected thresholds

The procedure is described in detail in Coles (2001). Only a short summary is given below:

(1) Let all losses $X_{1}, X_{2} \ldots, X_{i}$ of a time series be a sequence of independent and identically distributed variables, having a marginal distribution function $F$. Extreme events are those of the $X_{i}$ which exceed a threshold $u$.

(2) $u$ is set in a simple way by considering the highest 600 events of the time series for meteorological index $(M I)$ and loss index $(L I)$ Core Europe, or rather 300 events for $L I$ of each country, which equates to a return period (RP) of 0.2 or $0.4 \mathrm{yr}$. This choice is motivated by the fact that the estimated shape and scale parameters are stable above the chosen threshold after allowance for the sampling errors. This threshold is defined once per region or country for the recent climate $(3 \times 20 \mathrm{C}, 1960-2000)$.

(3) Having defined $u$, the parameters for the generalized Pareto distribution (GPD) are estimated via the maximum-likelihood-method. Accepted $y_{1} \ldots y_{k}$ are $k$ events exceeding $u\left(y_{k}=x_{k}-u\right)$. For shape parameters $\xi \neq 0$ the same method is also used. The parameters are obtained using numerical techniques.

(4) For a GPD with scale parameter $\sigma>0$ and shape parameter $\xi>0$, a suitable model for exceedance of $u$ by a variable $X$ is:

$$
\operatorname{Pr}\{X>u\}=\zeta_{u}\left[1+\xi\left(\frac{x-u}{\sigma}\right)\right]^{-\frac{1}{\xi}}, \zeta_{u}=\operatorname{Pr}\{X>u\}
$$

The estimation of $\zeta_{u}$, the probability of a loss to exceed $u$, is estimated via $\widehat{\zeta_{u}}$ which is the sample proportion of points exceeding $u$ :

$$
\widehat{\zeta_{u}}=\frac{k}{n}
$$

where $n$ is the number of all events of the time series.

The $N$-year return level is the level expected once every $N$ year and is defined for $\xi \neq 0$ by:

$$
z_{N}=u+\frac{\sigma}{\xi}\left[\left(N n_{y} \zeta_{u}\right)^{\xi}-1\right]
$$

where $n_{y}$ is the number of observations $\mathrm{yr}^{-1}$.

(5) The criteria for significance of RP changes at the 5\% significance level are based on non-overlapping GPD 83.4\% CIs (Julious 2004, their Table 2) calculated using the delta-method. Our sensitivity analysis revealed that the delta-method typically produces slightly wider CIs in comparison to the profile-likelihood-method (details in Coles 2001, Della-Marta et al. 2009), particularly for its lower bound (not shown). This may lead in some cases to slightly less frequent significant results. Nevertheless, due to the large number of samples considered here to fit the GPD (e.g. 200 events for LI Core Europe), the differences in CIs for the 2 methods are actually quite small (not shown). Thus, the choice of method to derive the CIs only marginally influences the results due to the large number of threshold exceedances used to fit the GPD. The deltamethod has the advantage of being easier to implement than the profile-likelihood-method.
Editorial responsibility: Richard Katz, Boulder, Colorado, USA
Submitted: July 27, 2011; Accepted: May 14, 2012

Proofs received from author(s): July 30, 2012 